\title{
A modular two yeast species secretion system for the production and preparative application of fungal peroxygenases
}

\author{
Pascal Püllmann ${ }^{1}$, Anja Knorrscheidt ${ }^{1}$, Judith Münch ${ }^{1}$, Paul R. Palme ${ }^{1}$, Wolfgang Hoehenwarter ${ }^{1}$, \\ Sylvestre Marillonnet ${ }^{1}$, Miguel Alcalde ${ }^{3}$, Bernhard Westermann ${ }^{1,2}$, Martin J. Weissenborn ${ }^{* 1,2}$ \\ ${ }^{1}$ Leibniz Institute of Plant Biochemistry, Weinberg 3, 06120 Halle (Saale), Germany \\ ${ }^{2}$ Institute of Chemistry, Martin-Luther-University Halle-Wittenberg, Kurt-Mothes-Str. 2, 06120 Halle \\ (Saale), Germany. \\ ${ }^{3}$ Department of Biocatalysis, Institute of Catalysis, CSIC, 28049 Madrid, Spain.
}

\section{Abstract}

Fungal unspecific peroxygenases (UPOs) are biocatalysts of outstanding interest. Providing access to novel UPOs using a modular secretion system was the central goal of this work. UPOs represent an enzyme class, catalysing versatile oxyfunctionalisation reactions on a broad substrate scope. They are occurring as secreted, glycosylated proteins bearing a haem-thiolate active site and solely rely on hydrogen peroxide as the oxygen source. Fungal peroxygenases are widespread throughout the fungal kingdom and hence a huge variety of UPO gene sequences is available. However, the heterologous production of UPOs in a fast-growing organism suitable for high throughput screening has only succeeded once-enabled by an intensive directed evolution campaign. Here, we developed and applied a modular Golden Gate-based secretion system, allowing the first yeast production of four active UPOs, their one-step purification and application in an enantioselective conversion on a preparative scale. The Golden Gate setup was designed to be broadly applicable and consists of the three module types: i) a signal peptide panel guiding secretion, ii) UPO genes, and iii) protein tags for purification and split-GFP detection. We show that optimal signal peptides could be selected for successful UPO secretion by combinatorial testing of 17 signal peptides for each UPO gene. The modular episomal system is suitable for use in Saccharomyces cerevisiae and was transferred to episomal and chromosomally integrated expression cassettes in Pichia pastoris. Shake flask 
productions in Pichia pastoris yielded up to $24 \mathrm{mg} / \mathrm{L}$ secreted UPO enzyme, which was employed for the preparative scale conversion of a phenethylamine derivative reaching $98.6 \%$ ee. Our results demonstrate a rapid workflow from putative UPO gene to preparative scale enantioselective biotransformations.

\section{Introduction}

Fungal unspecific peroxygenases (UPOs) have recently emerged as novel hydroxylation biocatalysts. They solely rely on hydrogen peroxide as cosubstrate reaching impressive total turnover numbers on $\mathrm{sp}^{3}$-carbon hydroxylations of up to $300,000^{1-4}$. There is an estimated number of more than 4000 putative UPO genes currently annotated and widely spread within the fungal kingdom representing just a small fraction of the available genetic diversity ${ }^{5}$. To provide further insight into the natural function of UPOs as well as broadening the available substrate scope, it is crucial to access more enzymes from diverse phylogenetic backgrounds. It would be desirable to heterologously produce these enzymes utilising fast-growing standard laboratory hosts such as bacteria or yeast. These organisms would facilitate protein engineering and allow directed evolution campaigns for tailoring desirable traits. Although substantial work has been invested into the heterologous expression of the first discovered Agrocybe aegerita UPO (AaeUPO) using the yeast Saccharomyces cerevisiae, sufficient protein amounts of $8 \mathrm{mg} / \mathrm{L}$ were obtained as the result of an intensive directed evolution campaign ${ }^{6}$. This fundamental work led to several successful UPO studies on a range of substrates from agrochemicals to pharmaceuticals $\mathrm{s}^{7-10}$.

The successful production was achieved by the introduction of nine amino acid exchanges. Four of these were localised within the 43 amino acid signal peptide, which orchestrates protein secretion in the natural fungal host as well as in S. cerevisiae. The engineered signal peptide combined with the wildtype AaeUPO enzyme resulted in a 27 -fold increase in protein secretion yield highlighting the paramount importance of the signal peptide for heterologous production as already shown by others ${ }^{11-}$ 
${ }^{16}$. Recent studies reported the production of UPOs in E. coli ${ }^{17,18}$. However, it remains elusive whether these recombinant peroxygenases harbour comparable activities and stabilities to UPOs produced in eukaryotic hosts. The reported expression yields are substantially lower when compared to $S$. cerevisiae raising the question, whether enough functional protein could be produced for laboratory evolution campaigns.

Golden Gate cloning has proven to be an invaluable synthetic biology tool enabling seamless assembly of gene fragments utilising type Ils restriction enzymes ${ }^{19-27}$. It can be performed in an affordable and straightforward one-pot, one-step digestion-ligation setup with efficiencies of correct assembly close to $100 \%$. Golden Gate cloning utilises type Ils restriction enzymes like Bsal or Bbsl, which are characterised by their ability to cut outside of their respe ctive recognition sequence and leads to the creation of defined 4 base pair sticky overhangs. These overhangs can be specified by PCR, allowing a sequence defined, efficient and seamless assembly of nine and more gene fragmentsin a one-pot and one-step manner $20,27,28$.

For the detection of the target protein secretion in small volumetric amounts of yeast supernatant, a sensitive, high-throughput suitable, and protein-specific assay would be highly beneficial. Previously reported split-GFP (green fluorescent protein) systems, which rely on tagging the protein of interest with a short 15 amino acid peptide tag and subsequent GFP reconstitution, present an ideal tool for this task ${ }^{29,30}$. Superfolder GFP (sfGFP) possesses a classical $\beta$-barrel protein fold, built up out of eleven $\beta$-sheets. By genetic removal of one $C$-terminal beta-sheet (GFP11), the fluorescence signal of the remaining protein (GFP1-10) is quenched. Using the GFP11 peptide as protein-tag hence allows the specific measurement of target protein amounts by fluorescence using GFP1-10as detector fragment, since upon interaction of both parts, the fluorescence of sfGFP is restored.

In this study, we envisioned a tripartite Golden Gate-based modular system. This system consists of the modules 'signal peptide', 'UPO gene' and 'protein-tag' (Fig. 1a). The 'protein-tag' module combines the affinity-based purification as well as the enzyme quantification by split-GFP. This S. cerevisiae 
expression system gave rise to a rapid workflow from UPO gene to heterologously produced and purified UPOs.

To give access to higher protein amounts, we designed two fully compatible episomal and one integrative plasmid for UPO production in the methylotrophic yeast Pichia pastoris (syn. Komagataella phaffii). In total, four active UPOs were heterologously produced in yeast for the first time. The obtained UPO yields using P. pastoris enabled the enantioselective hydroxylation of a phenethylamine derivative on a preparative scale.

\section{Results}

The modular Golden Gate UPO expression system. Three modules were designed for pre-defined assembly into an episomal S. cerevisiae shuttle expression plasmid. We created 32 modules consisting of 17 signal peptides (Module 1), 8 UPO genes (Module 2) and 7 protein-tags (Module 3, Fig. 1a). Module 3 is employed for affinity-based enzyme purification and/or split-GFP-based protein quantification. To verify the envisioned system for protein quantification, the $C$-terminal GFP11 detection tag (Module 3) was assembled with the previously evolved UPO signal peptide Aae-UPO* (Module 1) and the engineered peroxygenase AaeUPO* (Module 2) ${ }^{6,31}$. The successful split-GFP assay was validated by a significant fluorescence response in the sample with the secreted protein (Fig. 1b). Module 1, exhibiting 17 distinct signal peptides (SP), is the pivotal part for guiding the protein secretion. The signal peptide library consists of sequences originating from S. cerevisiae, further yeast organisms, basidiomycetes, ascomycetes and animals (Supplementary Table 2). Seven signal peptide sequences originate from (putative) UPOs or a closely related chloroperoxidase (CfuCPO). To demonstrate the importance of the signal peptide, we assembled the AaeUPO* gene (Module 2) and the GFP11 tag (Module 3) with each of the 17 signal peptides (Module 1). UPO secretion levels were monitored by enzymatic activity using the 5 -nitro-1,3-benzodioxole (NBD) ${ }^{32}$ assay as well as split-GFP detection (Fig. 1c). 
All constructs showed significant secretion levels and enzymatic activities. The signal peptides Cci-UPO, Ani- $\alpha$ Amylase, Sce- $\alpha$ Galactosidase and Gga-Lysozyme led to similar protein concentrations as the evolved signal peptide Aae-UPO*. The signal peptide Gma-UPO resulted in a more than doubled activity and secretion of the AaeUPO* enzyme relative to the evolved Aae-UPO* signal peptide (220\% increase). This observation is particularly impressive considering that the signal peptide Aae-UPO* was evolved for the optimised secretion of AaeUPO* in S. cerevisiae by subjecting it to several rounds of directed evolution ${ }^{6}$. The signal peptide Gma-UPO originates from the putative Galerina marginata UPO (GmaUPO). When correlating normalised enzymatic activity and split-GFP-based fluorescence values of the signal peptide library, in most cases, higher fluorescence levels were measured than activity values. This observation indicates the occurrence of differing AaeUPO* enzyme variants depending on respective signal peptide cleavage. This could be due to the great diversity of the utilised signal peptides likely resulting in differing $\mathrm{N}$-termini and affecting the enzymatic activity of the processed enzyme.

To give rise to a general, one-step protein purification protocol for UPOs, Module 3 was further extended to allow for simultaneous affinity-based protein purification and GFP11 based fluorescence detection. Several versions of the GFP11 tag in combination with Strep ${ }^{\circledR}$ - or Hexa/Octahistidine-affinity tags were generated and tested (Supplementary Table 3$)^{33,34}$. We used the protein tags with the previouslyidentified combination of signal peptide (Gma-UPO, Module 1) and UPO (AaeUPO*, Module 2) and identified the TwinStrep-GFP11 protein tag. This tag consists of a double 8 amino acid Strep II tag (Twin-Strep ${ }^{\circledR}$-tag) ${ }^{35}$ and a $C$-terminal GFP11 sequence. Comparison of the modules GFP11 and TwinStrep-GFP11 revealed unaltered enzymatic activities but a significantly higher fluorescence response for the TwinStrep-GFP11 construct (Supplementary Fig. 2). This difference is probably due to better accessibility of the terminal GFP11 portion since the overall size of the tag is increased(27vs 59 amino acids), and several flexible linkers are included. SDS PAGE analysis revealed the successful onestep purification of the mature protein AaeUPO* (Fig. 1d). 
bioRxiv preprint doi: $\mathrm{https}$ ://doi.org/10.1101/2020.07.22.216432; this version posted July 22, 2020. The copyright holder for this preprint

(which was not certified by peer review) is the author/funder, who has granted bioRxiv a license to display the preprint in perpetuity. It is made available under aCC-BY-NC-ND 4.0 International license.

a
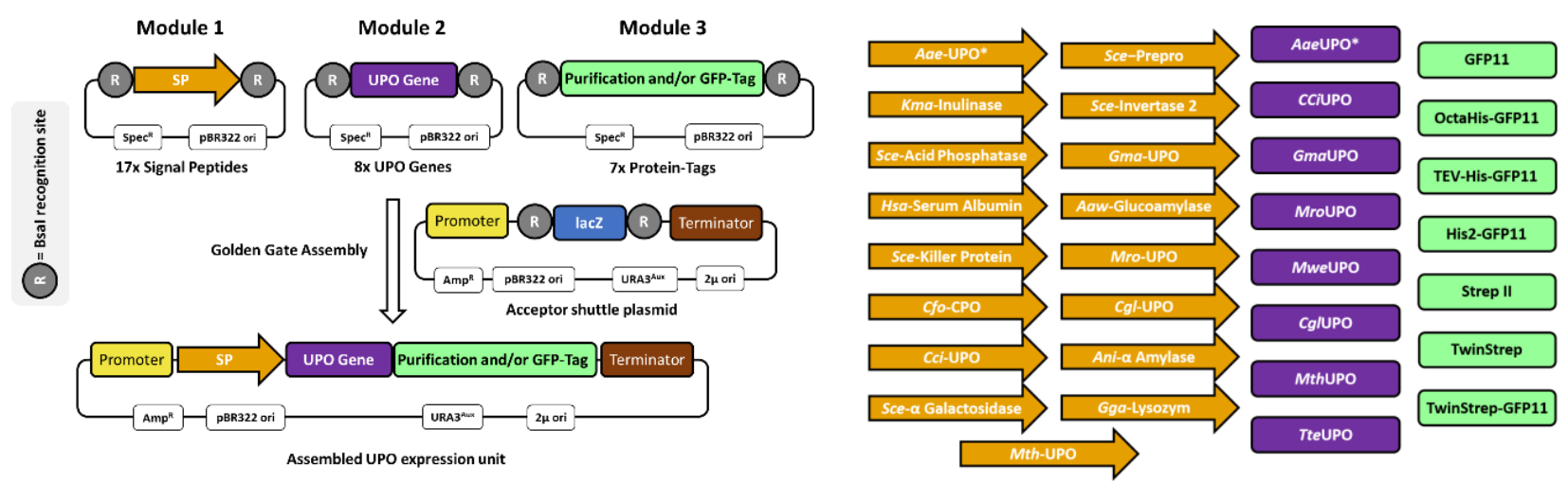

b
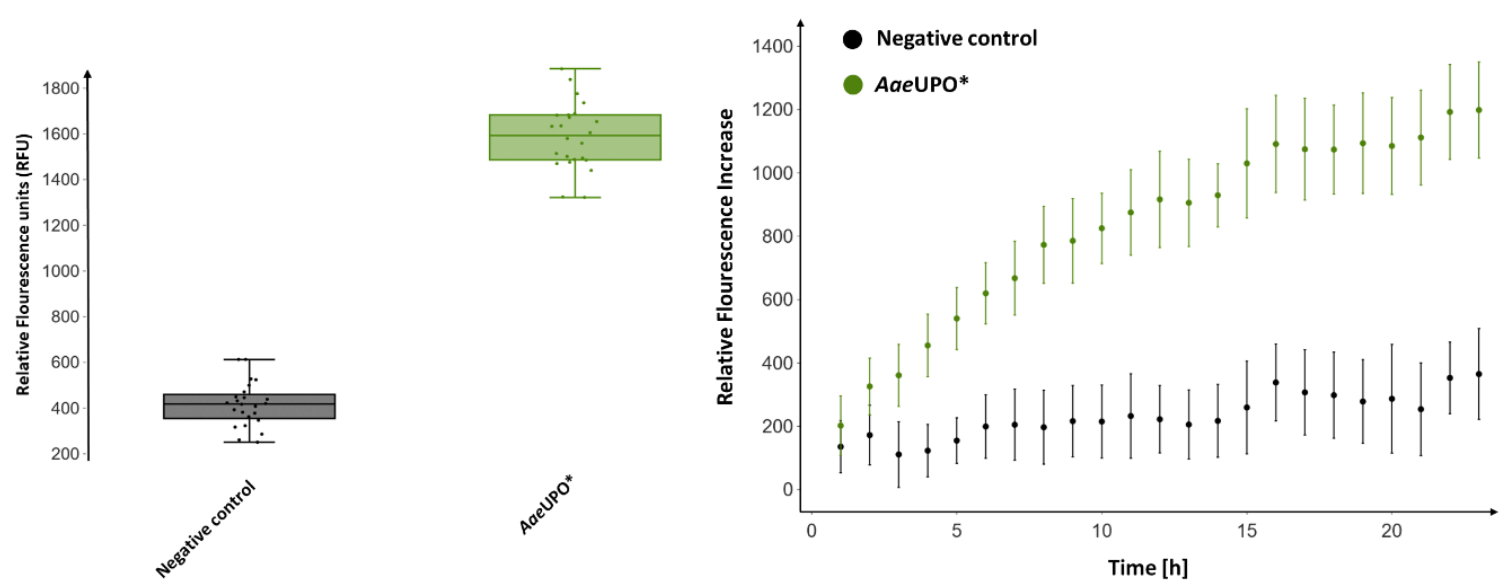

C

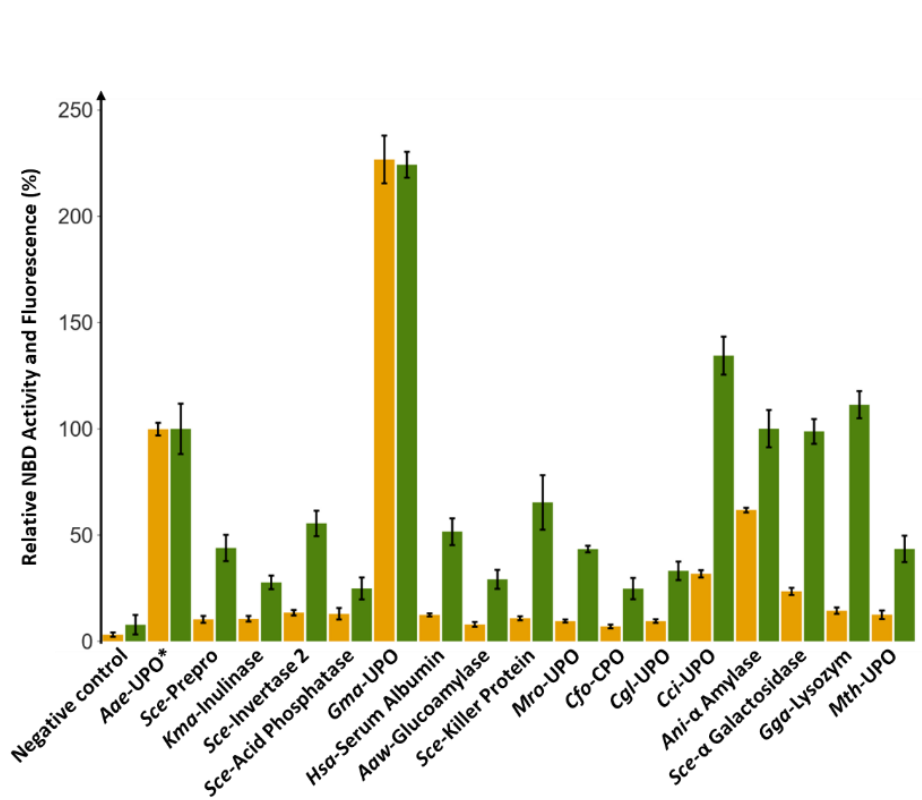

d

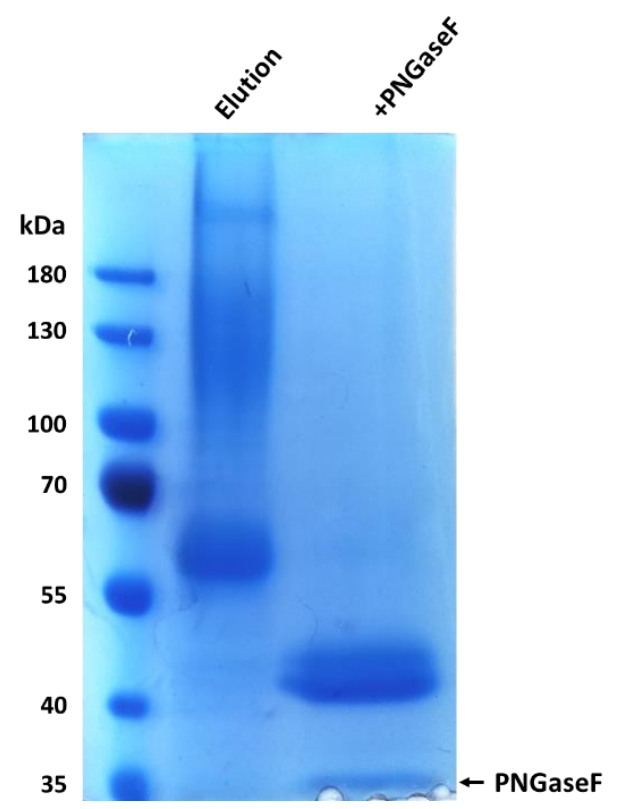

Fig. 1 The Golden Gate system consisting of the modules signal peptide, UPO gene and protein-tag and its functional verification regarding split-GFP assay, signal peptide shuffling and purification using the model UPO AaeUPO* in S. cerevisiae. a Left: Concept of the modular Golden Gate system as a tripartite system, consisting of signal peptide (SP; contains ATG start codon), UPOgene (lacking start and sto p codon) and C-terminal Tag (contains stop codon). Right: Overview of the individual parts of the modular shuffling systems, containing 17 signal peptides, 8 UPO genes and 7 C-terminal protein tags. Detailed sequence information of all parts can be found in Supplementary Table 2 and Supplementary Table 3. b Quantification of the UPO secretion in S. cerevisiae using the split-GFP system. Two constructs were utilised for testing, namely a previously derived yeast secretion variant of AaeUPO (AaeUPO*) and further including a Cterminal GFP11. The acceptor shuttle plasmid (pAGT572_Nemo 2.0) was used as negative control. Left: biological replicates ( $n=24)$ of AaeUPO* and the negative control were screened within the split-GFP assay. Relative fluorescence units (RFU) were measured at 0 and $72 \mathrm{~h}$ after adding GFP1-10. The values are shown as boxplots (AaeUPO*: median $=1589$, s.d. $8.9 \%$; negative control: median $=416$, s.d. $22.6 \%$ ) with individual data points shown as dots. Right: Continuous fluorescence measurements ( 24 hours; 23 time points) of each construct. Data are mean of fluorescence - background (background = first measurement after 1 hour $) \pm$ s.d. of biological replicates $(n=24)$. c Screening of the constructed signal peptide shuffling library utilising AaeUPO* as reference protein. Values for 5-nitro-1,3-benzodioxole (NBD) conversion (orange bars) and fluorescence by split-GFP assay (green bars) were normalised to the previously used AaeUPO SP*-AaeUPO* construct (100\%). Data are mean \pm s.6. of biological replicates $(n=5)$. Primary data are displayed in Supplementary Table 8. Detailed information on the origin and the sequence of the signal peptides can be found in Supplementary Table 2. $d$ SDS-PAGE of the purity of AaeUPO* after one step TwinStrep tag ${ }^{\circledR}$ purification, utilising the designed TwinStrep-GFP11 purification/detection combination tag. Additionally, AaeUPO* was subjected to enzymatic deglycosylation by PNGaseF and analysed (right lane). 
Utilisation of the modular system for the heterologous production of novel UPOs. To demonstrate that the modular system can provide quick access to UPOs, we picked seven UPO genes to be expressed in S. cerevisiae with three being undescribed putative UPOs. Four UPOs were previously described and were produced in their natural hosts-Marasmius rotula UPO (MroUPO $)^{36}$, Marasmius wettsteinii UPO (MweUPO) ${ }^{5}$, Chaetomium globosum UPO (Cg/UPO $)^{37}$-or are heterologously expressed in an Aspergillus oryzae strain (Coprinopsis cinerea UPO (CciUPO) $)^{38}$.

Two putative UPO sequences were selected based on sequence al ignments and data bank searches using the short-type peroxygenase Cg/UPO as a template. Two sequences were retrieved from fungi classified as thermophilic: Myceliophthora thermophila (MthUPO) and Thielavia terrestris (TteUPO) ${ }^{39}$, bearing $72 \%$ and $51 \%$ sequence identity to $C g /$ UPO, respectively. The predicted long-type UPO gene GmaUPO derived from the basidiomycete Galerina marginata and was selected based on its high sequence identity (71\%) with AaeUPO.

All genes were introduced as modules (Module 2) into the Golden Gate system and subjected to random shuffling utilising all 17 signal peptides (Module 1).

Out of the seven UPO genes, six were secreted in S. cerevisiae in combination with at least two signal peptides (Fig. 2a). CciUPO showed no secretion with any of the signal peptides. MweUPO and GmaUPO were identified by the split-GFP assay, but no activity was detected using the colourimetric 2,6dimethoxyphenol (DMP) assay ${ }^{8}$. MweUPO, MroUPO and Cg/UPO were the only UPOs, which showed the highest activities with their endogenous signal peptides, where MroUPO and MweUPO share the same native signal peptide. MthUPO and TteUPO showed remarkable secretion levels in the microtiter plate setup, leading to 17 -fold (MthUPO) and 50-fold (TteUPO) split-GFP signal intensities above background level. A high signal peptide promiscuity was observed for MthUPO and TteUPO with at least 5 and 8 suitable signal peptides, respectively (Supplementary Figs. 3 and 4).

Purification and characterisation of the identified UPOs. All secreted UPOs in combination with their best signal peptides were equipped with the TwinStrep-GFP11 tag, produced in $1 \mathrm{~L}$ shake flask scale 
and purified by affinity chromatography. The occurrence and primary sequence of each UPO was confirmed by tryptic digest and mass spectrometric peptide analysis (Supplementary Table 6). AaeUPO* analysis revealed the amino acids 'EPGLPP' being the first detectable residues at the $\mathrm{N}$ terminus in accordance with previous results ${ }^{40}$. This finding indicates that the new signal peptide GmaUPO leads to a comparable cleavage pattern as the evolved Aae-UPO* signal peptide. The split-GFP response and the NBD activity also exhibited the same ratio for both signal peptides (Fig. 1c), which further strengthens the point of a similar cleavage pattern. Both UPOs were produced utilising their native signal peptide (signal peptide annotated as Mro-UPO in both cases). Fragments derived from the signal peptide Mro-UPO (11 amino acids for MroUPO and 9 amino acids for MweUPO) were identified by MS analysis, suggesting a different cleavage pattern compared to the natural host 5 . Obtained $N$-termini of GmaUPO and MthUPO are in agreement with the predicted cleavage sites based on alignments with the enzymes AaeUPO* and Cg/UPO, respectively. The $N$-terminus of $C g / U P O$ could not be resolved. For TteUPO, a peptide fragment of 10 amino acids of the utilised signal peptide (ScePrepro) was identified.

GmaUPO and MweUPO were not further studied as the purified enzymes did not exhibit any activity towards the colourimetric peroxygenase substrates DMP and NBD. Biochemical parameters were therefore determined for MroUPO, Cg/UPO, MthUPO and TteUPO. UV absorption profiles showed the expected characteristic peroxygenase haem-thiolate features. A Soret band with a maximum around 420 nm (MroUPO: 419 nm; Cg/UPO: $418 \mathrm{~nm}$; MthUPO: $420 \mathrm{~nm}$ and TteUPO: $419 \mathrm{~nm}$ ) and two Q-bands in the range of 537 to 546 and 569 to $573 \mathrm{~nm}$ (Fig. 2B) ${ }^{2}$ were detected. Cg/UPO revealed a broader Soret band shape as well as less pronounced Q-bands. The respective carbon monoxide complex exhibited absorption maxima around $444 \mathrm{~nm}$ with a less detectable signal for MroUPO (Supplementary Fig. 5). 
bioRxiv preprint doi: https://doi.org/10.1101/2020.07.22.216432; this version posted July 22, 2020. The copyright holder for this preprint (which was not certified by peer review) is the author/funder, who has granted bioRxiv a license to display the preprint in perpetuity. It is made available under aCC-BY-NC-ND 4.0 International license.

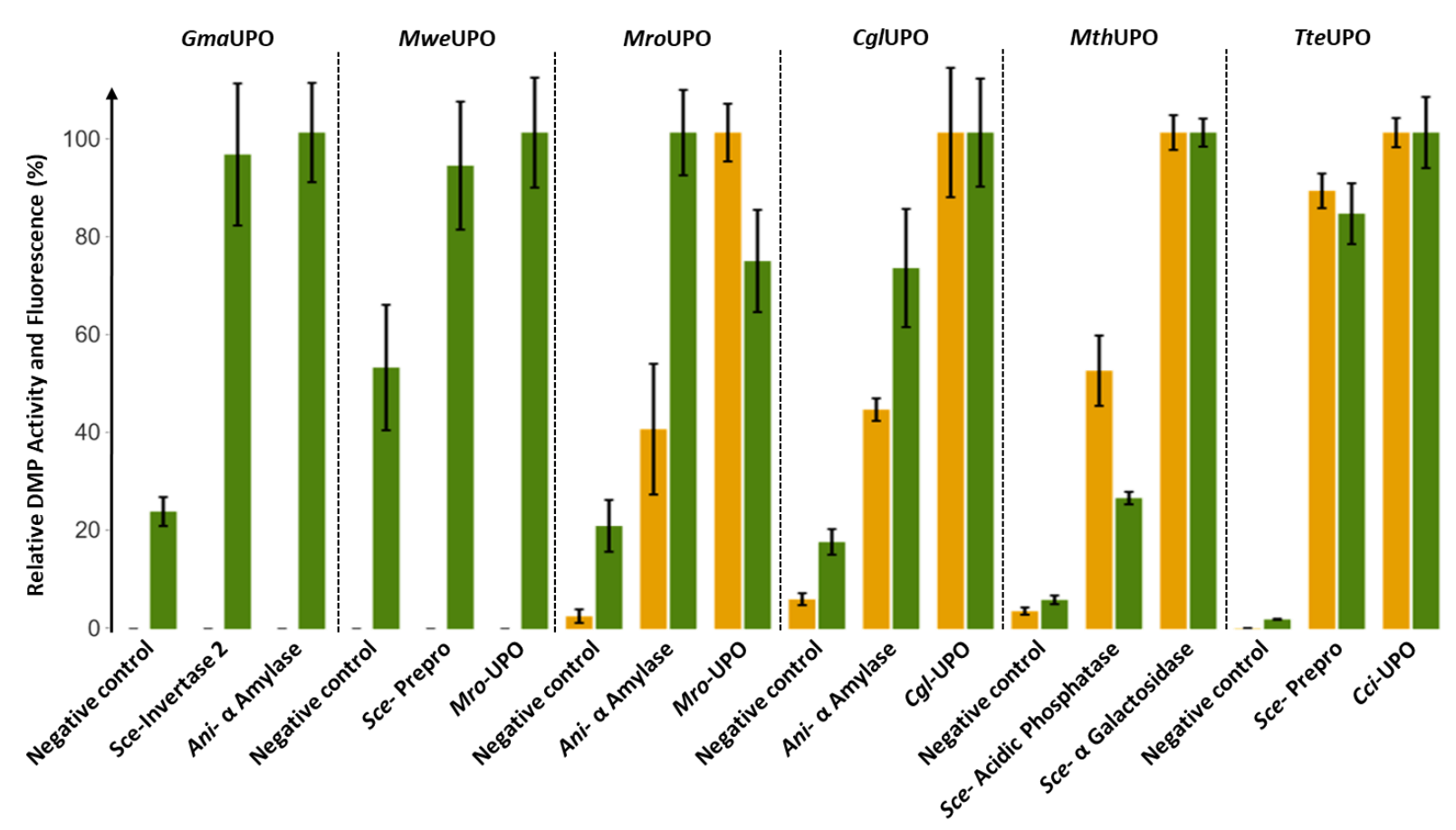

b

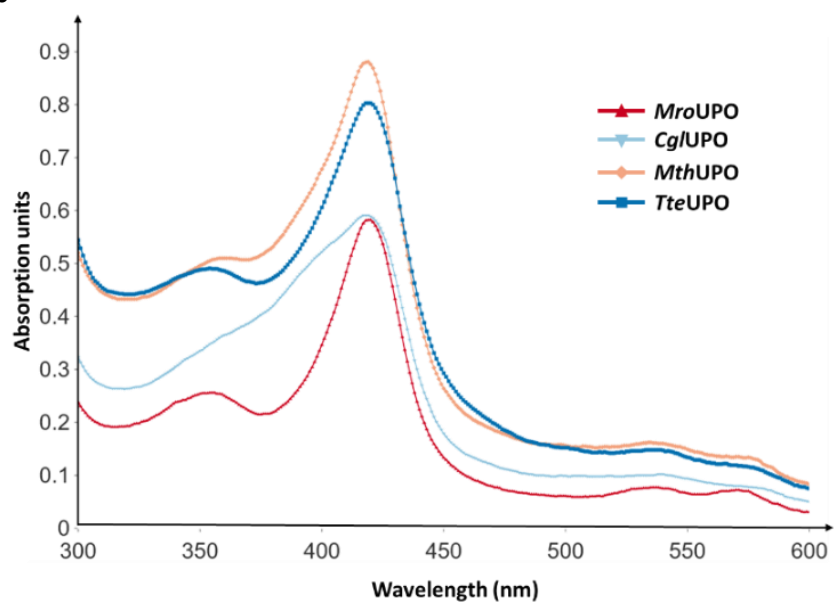

c

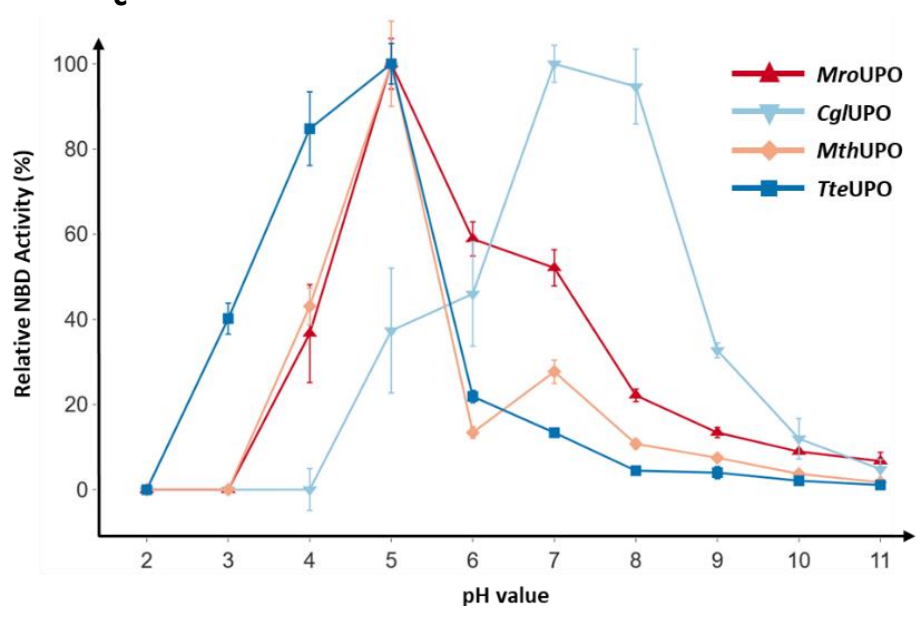

Fig. 2 Through signal peptide shuffling identified novel UPO construct and their analysis of UVabsorption spectra and pH profiles. a Golden Gate signal peptide shuffling was applied for the testing of described and putative UPO genes, and the two best signal peptide/UPO gene combinations are displayed. GmaUPO, MweUPO, MroUPO and Cg/UPO were screened in combination with a GFP11-tag. MthUPO and TteUPO were screened using the TwinStrep-GFP11 protein tag. UPO enzyme activity was determined by monitoring the conversion of 2,6-dimethoxyphenol (DMP) to cerrulignone. The highest average fluorescence (split-GFP) and conversion values (DMP) within one enzyme panel were set to $100 \%$, and the other values normalised accordingly. Data are mean \pm s.d. of biological replicates $(\mathrm{n} \geq 4)$. Corresponding primary data are displayed in Supplementary Table 9. b UV-Vis absorption spectra of the purified peroxygenases Mro UPO, Cg/UPO, MthUPO and TteUPO in the wavelength range between 300 and $600 \mathrm{~nm}$ (measurement interval: $1 \mathrm{~nm}$ ). c pH profiles of MroUPO, Cg/UPO, MthUPO and TteUPO catalysed enzymatic conversion of 5-nitro-1,3-benzodioxole (NBD) to 4-nitrocatechol. The highest mean activity of a respective enzyme was set to $100 \%$ and the other values normalised accordingly. Data are means \pm s.d. of measurements performed in triplicates. Corresponding primary data are displayed in Supplementary Table 10. 
Protein purity and glycosylation were analysed by SDS-PAGE. Native deglycosylation was performed using PNGaseF (Supplementary Fig. 6). All obtained molecular weights after deglycosylation were in agreement with the calculated primary sequence and the peptide analysis by mass spectrometry. MroUPO exhibited a weak band at approx. $42 \mathrm{kDa}$ that was retained after deglycosylation. Cg/UPO revealed a smeared band in the range of 55 to $130 \mathrm{kDa}$. Deglycosylation led to the occurrence of two distinct protein bands of approx. 37 and $33 \mathrm{kDa}$ indicating different protein subtypes. MthUPO and TteUPO showed an intensive smeared band in the range of 55 to $200 \mathrm{kDa}$. This smear was converted into distinct protein bands upon deglycosylation with approx. $38 \mathrm{kDa}$ and $36 \mathrm{kDa}$ for MthUPO and TteUPO, respectively.

To gain insights into the impact of the glycosylation for enzymes' activities, the UPOs were deglycosylated in the native state and assessed for their activity towards NBD (Supplementary Fig. 7). The enzymatic activity of Cg/UPO and MroUPO was not significantly and only by $30 \%$ reduced, respectively. The activity was substantially impaired for TteUPO and MthUPO, leading to a complete loss and approx. $85 \%$ decrease, respectively, in enzymatic activity.

We next evaluated the $\mathrm{pH}$-dependencies of the enzymes using NBD as a substrate (Fig. 2c). MroUPO, MthUPO and TteUPO exhibited a similar profile with maximum activityat slightly acidic conditions (pH 5), whereas Cg/UPO's activity optimum was at $\mathrm{pH}$ 7. TteUPO showed a broader tolerance towards lower $\mathrm{pH}$ values, retaining medium ( $\mathrm{pH} 3 ; 40 \%)$ and high activity $(\mathrm{pH} 4.0 ; 80 \%)$ at acidic conditions. The obtained valuesfor MroUPO and Cg/UPO are in good agreement with previous data obtained with homologously produced enzyme 36,37. $^{3}$.

Enzymatic epoxidation and hydroxylation experiments. The heterologously produced UPOs were tested towards their substrate specificity and activities by investigating three distinct reaction types: aromatic hydroxylation ( $\mathrm{sp}^{2}$-carbon), epoxidation of an alkene and the benzylic hydroxylation ( $\mathrm{sp}^{3}$ carbon) of phenylalkanes with varying alkyl chain lengths from two to five carbons (Fig. 3). All reactions were performed at the same conditions and assessed for the achieved turnover number (TON) within 
one hour. Substantially differing behaviour could be observed between AaeUPO* and the novel heterologously produced UPOs regarding substrate conversion, specific product formation and stereoselectivity. AaeUPO* proved to be the only enzyme displaying a high specificity for single hydroxylation of naphthalene leading to 1-naphthol (92\% of the formed product, Fig. 3a). The other UPOs exhibited a strong tendency for further oxidation leading to the dione product 1,4naphthoquinone. The epoxidation of styrene (Fig. 3b) was efficiently catalysed by AaeUPO* (4580 TON) in combination with a poor stereoselectivity ( $2 \%$ ee). Cg/UPO exhibited comparable epoxidation activities (4110 TON) and an enantioselectivity of $44 \%$ ee. For MthUPO, TON decreased to 1100 but revealed the highest stereoselectivity $(45 \%$ ee). The studies of the benzylic hydroxylation of phenylalkanes-phenylethane to phenylpentane-confirmed the preference of AaeUPO* towards short alkane chain length (Fig. 3c) 3 $^{3}$ Starting from 4500 turnovers for the conversion of phenylethane and deteriorating to no product formation and only traces of benzylic hydroxylation using phenylbutane and phenylpentane, respectively (for other product formations see Supplementary Fig. 15). Cg/UPO and MthUPO exhibited an inverted trend with increasing product formations for longer alkyl chain lengths, exhibiting the lowest activity for the phenylethane hydroxylation.

The highest activity was detected in both casesusing phenylbutane (Cg/UPO: 1670TON, MthUPO: 1490 TON) with only slightly decreased activity for phenylpentane as a substrate and the only significant side-product being the further oxidation of the benzylic alcohol to the corresponding ketone (Supplementary Fig. 15). TteUPO showed a similar preference towards long-chain phenylalkanes with the highest TON for phenylpentane conversion (500 TON). TteUPO represented the only UPO with a significant specificity towards the formation of the S-enantiomer for phenylpropane and phenylbutane. For phenylpentane, it revealed the formation of the opposite alcohol enantiomer than the other tested UPOs. 


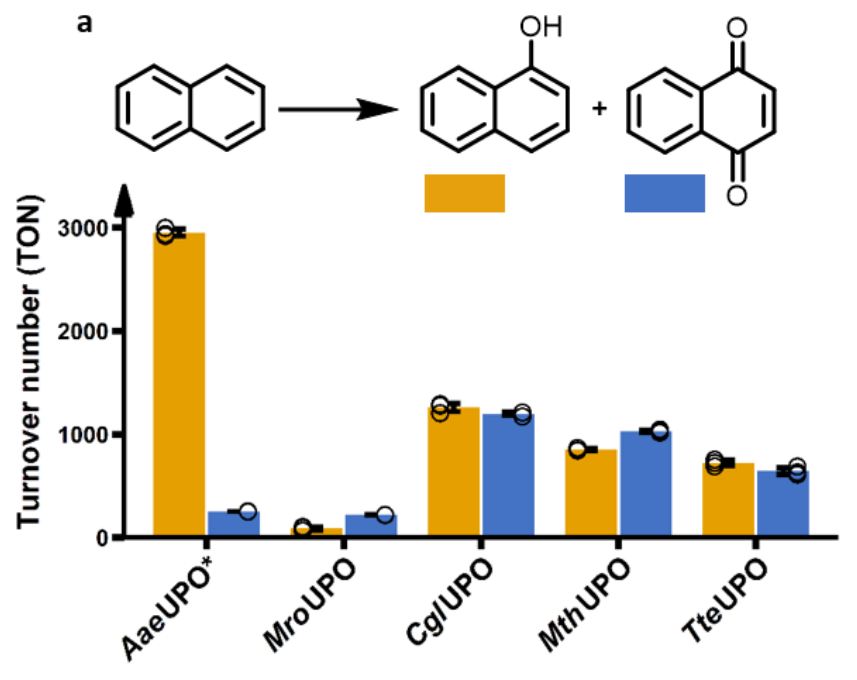<smiles>C(=C\c1ccc(C2CO2)cc1)\C=C\c1ccccc1</smiles>
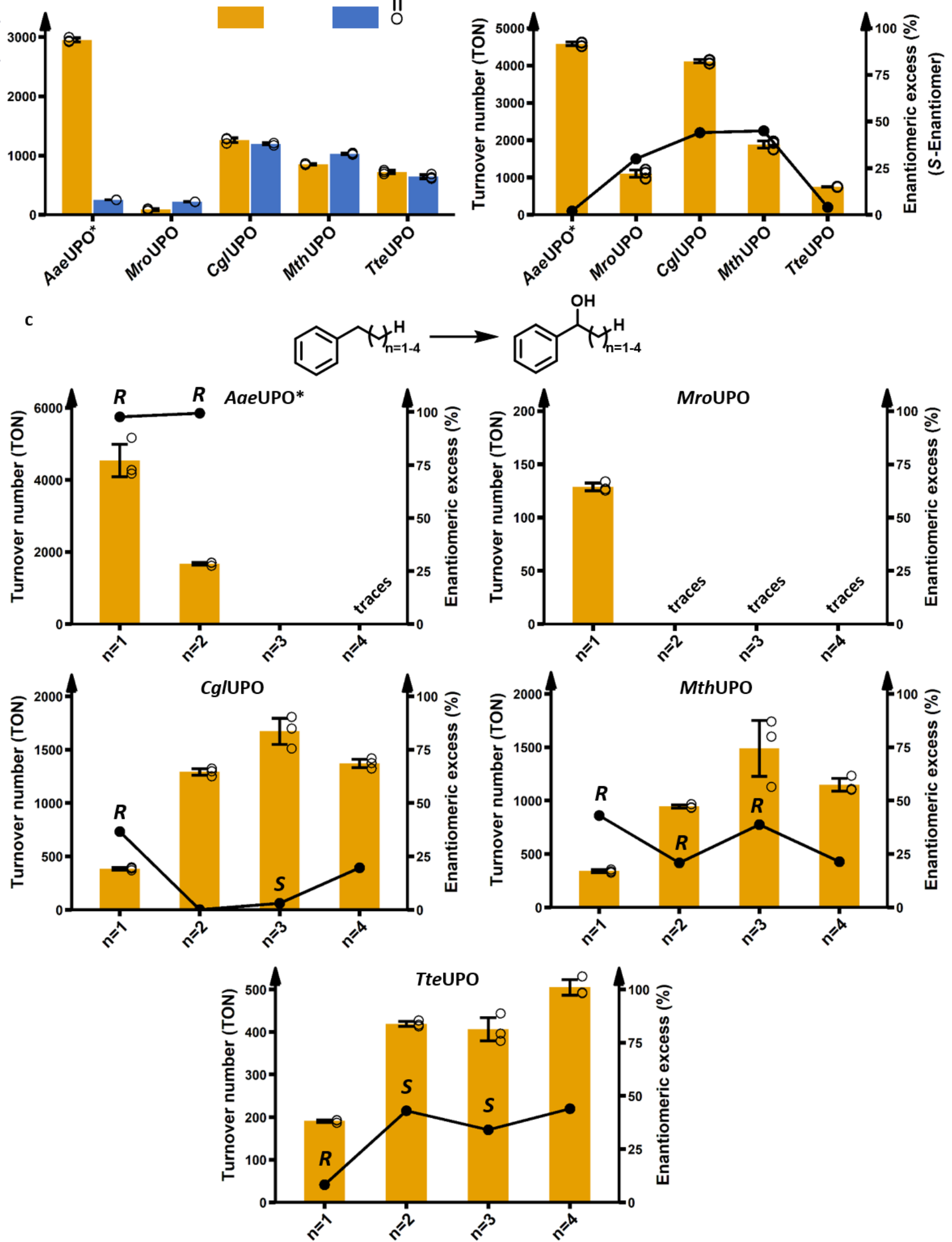

Fig. 3 Enzymatic activity assessment of the peroxygenases regarding aromatic hydroxylation, epoxidation and sp ${ }^{3}$-carbon hydroxylation. All reactions were performed for $1 \mathrm{~h}$ using $1 \mathrm{mM}$ of substrate. Bar charts display the obtained turnover numbers (TON) within one hour. The lines correspond to the enantiomeric excess \%. Data are mean \pm s.d. measurements derived from biological triplicates with individual data points shown as circles. See supplementary information for further details. a Conversion of naphthalene to naphthol and 1,4-naphthoquinone. b Conversion of styrene to styrene oxide. c A homologous row of phenylethane, phenylpropane, phenylbutane and phenylpentane hydroxylation, res pectively focusing on hydroxylation of the benzylic carbon. The alcohol enantiomer is indicated by an (R) or (S). The exact enantiomer for phenylpentane was not determined. See Supplementary Fig. 14 for occurrence of side-products. For MroUPO conversion of phenylethane no enantioselectivity could be determined. 
Expanding the modular UPO secretion system to Pichia pastoris. The methylotrophic yeast $P$. pastoris

(syn. Komagataella phaffii) constitutes an attractive heterologous production host with a steadily growing toolbox of valuable synthetic biology parts such as plasmids, promoters and signal peptides $^{41,42}$. P. pastoris can reach high cell densities, efficiently perform post-translational modifications such as glycosylationand disulfide-linkage and offers a set of strong and tightly regulated promoters for target gene expression. Amongst other factors, these properties render $P$. pastoris a widely used eukaryotic host for the large scale industrial production of therapeutic proteins and industrial enzymes ${ }^{43}$. We investigated the adaptation of the modular system for use in $P$. pastoris. Therefore two novel episomal P. pastoris expression plasmids were designed and assembled. They contain a previously described autonomously replicating sequence coined panARS, which confers episomal stability and a hygromycin B marker gene for antibiotic selection ${ }^{44,45}$. The constructed episomal plasmids differ by the employed promoter: the strong constitutive glyceraldehyde-3phosphate dehydrogenase promoter ( $P_{\mathrm{GAP}}$, plasmid pPAP001) and the recently described strong methanol inducible catalase promoter $\left(P_{\text {CAT1 }}, \text { PPAP002 }\right)^{46}$. The plasmids were constructed to allow direct implementation of the tripartite modular UPO secretion system, consisting of Module 1 (signal peptide), Module 2 (UPO gene) and Module 3 ( $C$-terminal tag, Fig. 4a; left). To further allow the genomic integration to generate stable $P$. pastoris cell lines for antibiotic-free large scale enzyme production in shake flasks or fermenters, a third plasmid (pPAP003) was constructed. The episomal plasmids are designed to enable direct transfer of the identified best transcription unit (promotersignal peptide-gene-tag-terminator) combination to the integration plasmid. This transfer requires only an additional Golden Gate assembly reaction using the restriction enzyme Bbsl (Fig. 4a; right). 
bioRxiv preprint doi: https://doi.org/10.1101/2020.07.22.216432; this version posted July 22, 2020. The copyright holder for this preprint (which was not certified by peer review) is the author/funder, who has granted bioRxiv a license to display the preprint in perpetuity. It is a Module 1 Module 2 made available 3 under aCC-BY-NC-ND 4.0 International license.

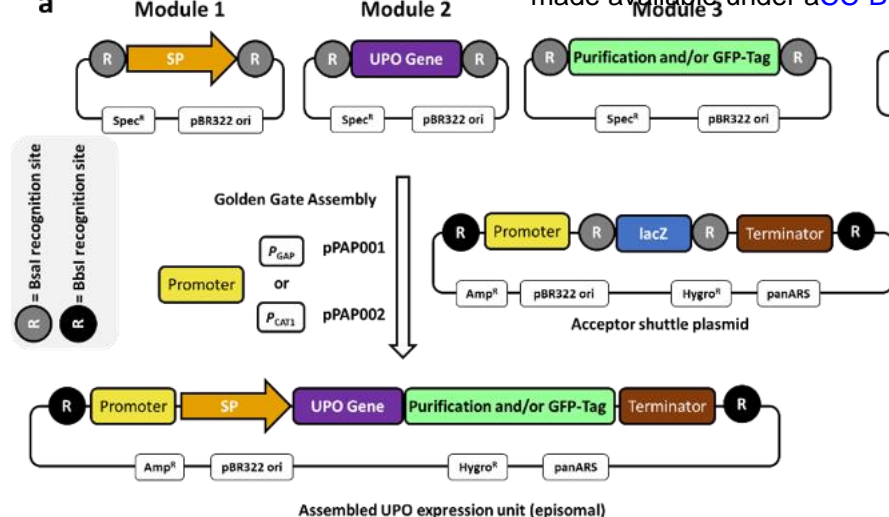

b
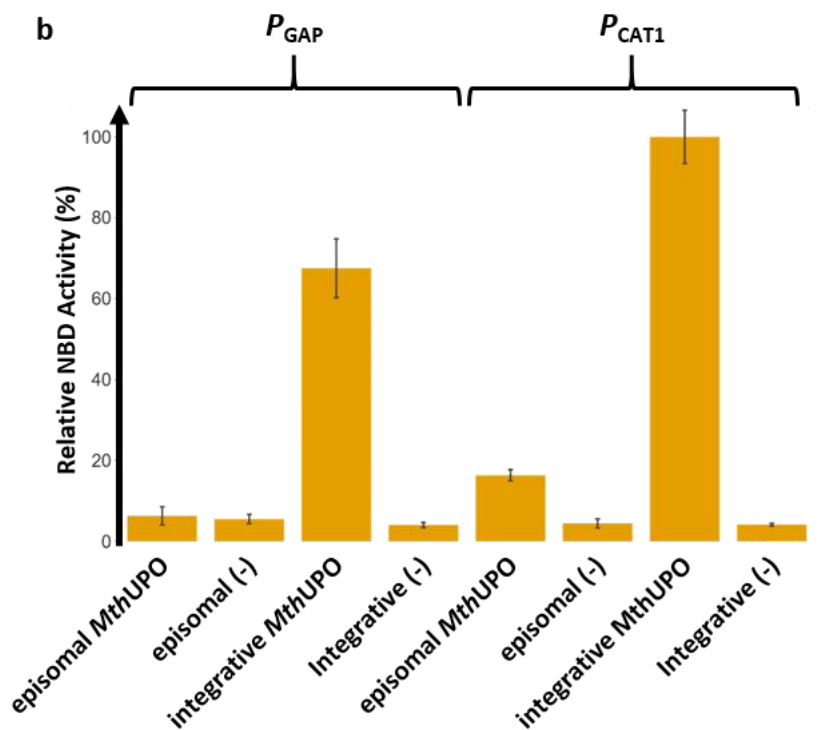

d

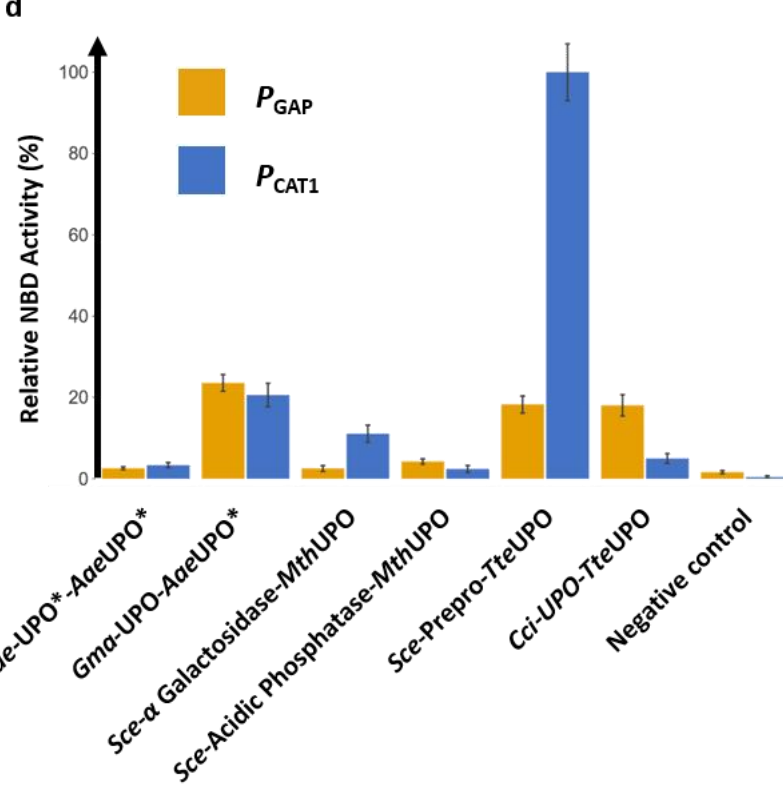

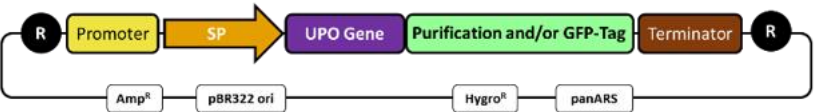

Hygro ${ }^{R}$ PanARS
C

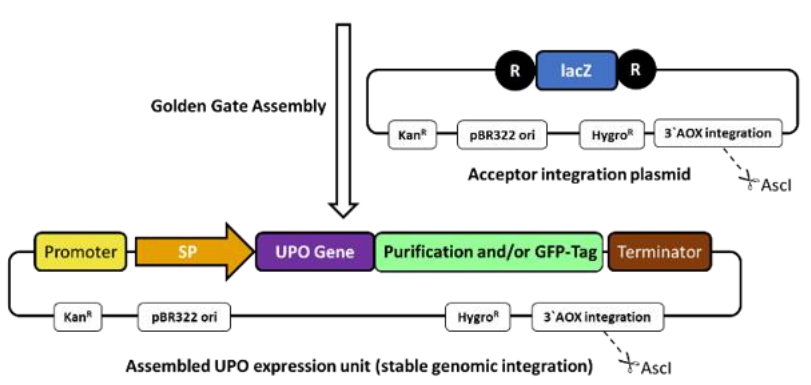

$P_{\text {CAT1 }}$

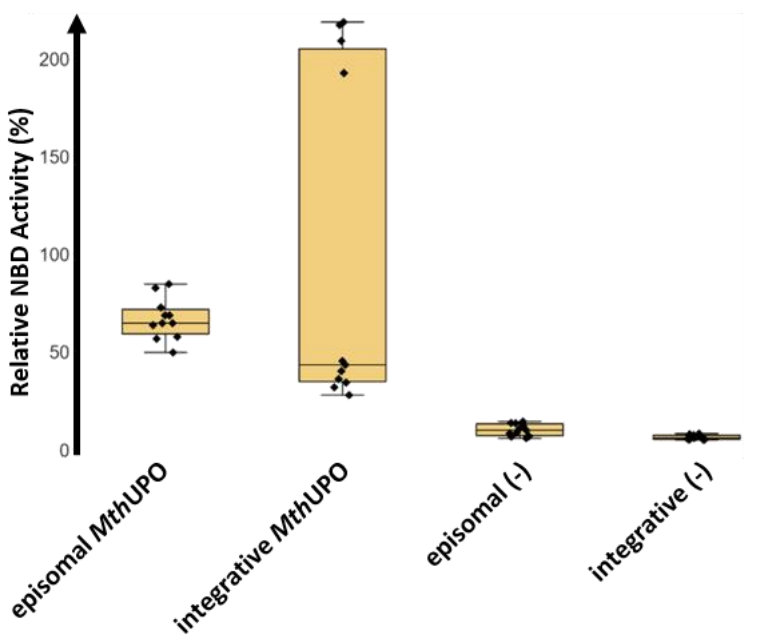

e

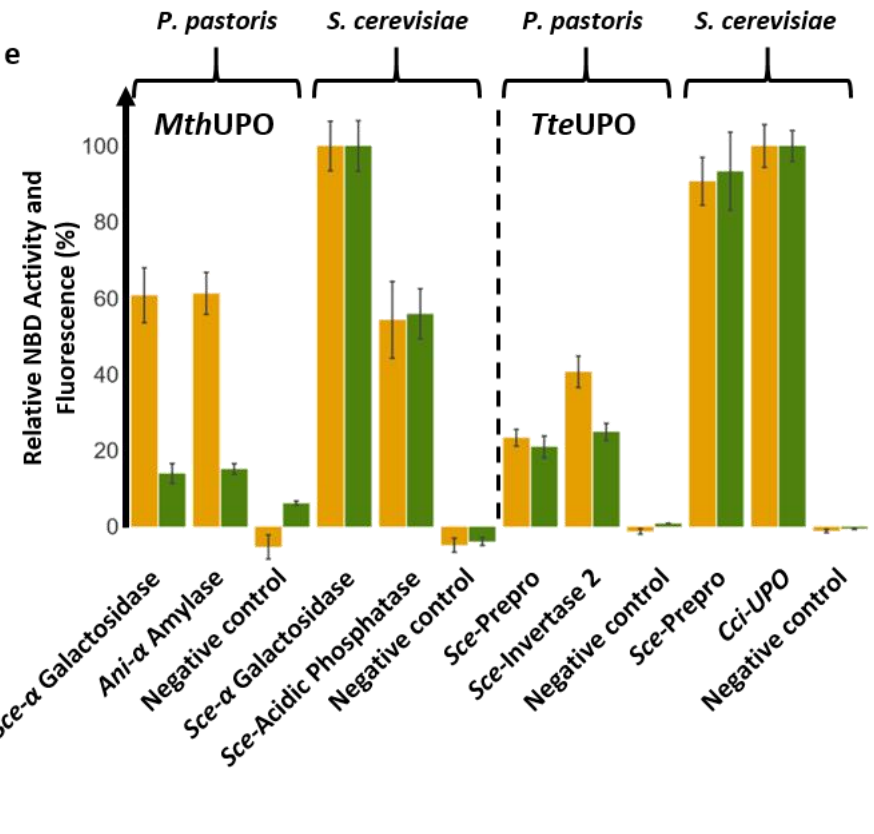

Fig. 4 The compatible modular Golden Gate setup utilising episomal and integrative P. pastoris plasmids and its application. a Left: Overview of the designed episomal $P$. pastoris screening setup. All previously created basic modules are compatible to be used within this system. Two episomal plasmids wer e designed harbouring the constitutive strong promoter $P_{\text {GAP }}$ or the strong inducible promoter $P_{\text {CAT1. }}$. Right: Identified gene constructs can be directly transferred in a one-pot Golden Gate reaction $(B b s \mid)$ from the episomal plasmid to an integrative plasmid. After linearisation (Ascl digest) this plasmid can be integr ated into the genomic 3 'AOX region of $P$. pastoris. b Comparison of relative activities of 5-nitro-1,3-benzodioxole (NBD) conversion for different $P$. pastoris constructs bearing the tripartite combination of $\alpha$ Galactosidase signal peptide-MthUPO-TwinStrep-GFP11. $P_{\text {GAP }}$ bearing constructs were screened utilising Glucose $(1.5 \%(\mathrm{w} / \mathrm{v}))$ as sole carbon source. $P_{\text {CAT1 }}$ bearing constructs were screened utilising a dual feeding strategy $(0.5 \%(\mathrm{v} / \mathrm{v})$ glycerol and $1.5 \%(\mathrm{v} / \mathrm{v})$ methanol) as primary and inducible carbon so urces. The highest expression mean is set to 100 $\%$ and all data normalised. Data are mean \pm s.d. of biological replicates $(n=6)$ originating from streak outs of one previously screened colony of the respective construct. $c$ Comparison of relative activities of NBD conversion of $P_{\text {CAT1 }}$ based constructs bearing the tripartite combination of $\alpha$ Galactosidase signal peptide-MthUPO-TwinStrepGFP11. Box plots of biological replicates $(n=11)$ of individual $P$. pastoris colonies for each construct. The highest expression mean is set to $100 \%$ and all data normalised (episomal MthUPO: median =65, s.d. $15.0 \%$; integrative MthUPO: median =44, s.d. $83.3 \%$; episomal (-): median =10, s.d. $28.2 \%$; integrative (-): median =6, s.d. $16.4 \%$ ). d Comparison of relative activities of NBD conversion for different episomal $P$. pastoris constructs (6 biological replicates each) using the indicated signal peptide-UPO combinations as well as a TwinStrep-GFP11 tag. $P_{\text {GAP }}$ (yellow bars) and $P_{\text {CAT1 }}$ (blue bars). The highest expression is set to $100 \%$, and all data are normalised. Data are mean \pm of biological replicates $(n=6)$. e Direct comparison of episomal UPO production of theld 4 ro best signal peptide-UPO combinations for MthUPO and TteUPO as identified by a previously performed signal peptide shuffling approach in both yeast species. Episomal $P$. pastoris expressions utilised the $P_{\text {CAT1. }}$. The highest mean expression and activity for each enzyme is set to $100 \%$, and all data are normalised. Data are mean \pm s.d. of biological replicates $(n=6)$. NBD conversion activity (orange) and relative fluorescence 
We tested all P. pastoris plasmids using the newly discovered peroxygenase MthUPO in combination with the Sce- $\alpha$ Galactosidase signal peptide. The constructs proved to be functional and led to an NBD conversion signal (Figure $4 \mathrm{~b}$ ). $P_{\text {GAP }}$ based secretion was generally lower in comparison to $P_{\text {CAT1 }}$, and the episomal $P_{\text {GAP }}$ UPO activity was not distinguishable from the negative control. The integrative plasmids outperformed their episomal counterparts significantly with a factor of 5 for $P_{\text {CAT1 }}$. A similar observation however in a varying degree was made testing the enzymes AaeUPO* and TteUPO (Supplementary Fig. 8), indicating that the integrative constructs are promoting higher UPO secretion levels than their episomal counterparts.

To gain insights into interclonal variabilities of UPO secretion, episomal and integrative plasmids were transformed into $P$. pastoris. Individual colonies were cultivated and tested for UPO secretion. The episomal construct showed diminished mean activity but a substantially lower clonal variability than the integrative plasmid when tested with NBD (Fig. 4c). This high variability of the secretion level for the integrative plasmid is presumably due to diffe rent numbers of copy insertions into the $P$. pastoris genome, which might also lead to different colony sizes (Supplementary Fig. 9).

To investigate and compare the secretion levels of episomal $P_{\mathrm{GAP}}$ and $P_{\mathrm{CAT} 1}$ harbouring plasmids, twelve constructs were generated harbouring the peroxygenases AaeUPO*, MthUPO and TteUPO. All promoter combinations $\left(P_{\mathrm{GAP}}\right.$ and $\left.P_{\mathrm{CAT} 1}\right)$ and the two previously identified signal peptides were constructed in combination with the respective UPO gene and analysed for NBD activity. All constructs resulted in a significant NBD conversion (Fig. 4d). The previously observed $220 \%$ improved AaeUPO* secretion in S. cerevisiae by combining AaeUPO* with the signal peptide Gma-UPO was found to be even more pronounced using the episomal $P$. pastoris constructs ( $P_{\text {CAT1 }}: 620 \%$ ). Besides the striking influence of the promoter on the secretion level, also the combination of the signal peptide and the promoter proved to be pivotal. For TteUPO, using the promoter $P_{\text {CAT1 }}$ in combination with the ScePrepro signal peptide led to the highest detected activity with a 20 -fold higher signal compared to the CCi-UPO signal peptide. The same signal peptide variations employing the $P_{\text {GAP }}$ promoter, however, resulted in similar secretion levels. This demonstrates besides the crucial role of the chosen signal 
peptide (Fig. 1c and 2a) an additionally pivotal influence of the promoter/signal peptide combination on the UPO secretion.

To gain insights into the different signal peptide preferences for secretion in P. pastoris, the signal peptide shuffling approach was repeated in $P$. pastoris, choosing the episomal $P_{\text {CAT1 }}$ bearing plasmid (Supplementary Figs. 10 and 11). For MthUPO the signal peptides Sce- $\alpha$ Galactosidase and Ani- $\alpha$ Amylase proved to be most suitable, and Sce- Prepro and Sce-Invertase 2 were identified as top hits for TteUPO. Interestingly, Sce-Invertase 2 has not been identified amongst the top hits in S. cerevisiae whereas the best signal peptide (Cci-UPO) for secretion in S. cerevisiae (Fig. 4d) was not identified in the $P$. pastoris screen.

To compare episomal S. cerevisiae and P. pastoris secretion, the two best performing constructs for MthUPO and TteUPO were selected. This species comparison (Fig. 4e) indicates that the episomal S. cerevisiae secretion is superior to the episomal P. pastoris production. In the case of MthUPO, both $P$. pastoris constructs led to approx. $60 \%$ of NBD conversion in comparison to the most suitable $S$. cerevisiae construct while already exhibiting higher NBD conversion rates than the second most suitable signal peptide for secretion in S. cerevisiae (Sce- Acidic Phosphatase). The split-GFP fluorescence assay revealed a diminished response for the $P$. pastoris setup relative to the S. cerevisiae constructs. Regarding TteUPO, the best $P$. pastoris construct (Sce-Invertase 2 ) led to approx. $40 \%$ of relative NBD conversion when compared to the best S. cerevisiae construct (Cci-UPO). For TteUPO the split GFP assay followed a linear pattern when comparing species, without revealing a diminished response for $P$. pastoris.

Comparison of shake flask UPO production in P. pastoris and S. cerevisiae. By using the constructed integrative plasmid pPAPO03 and the $P_{\text {CAT1 }}$ promoter, stable $P$. pastoris cell lines were constructed for the production of five UPOs: AaeUPO*, MroUPO, Cg/UPO, MthUPO and TteUPO (Fig. 5a). Utilising P. pastoris led to substantially higher production titres in all cases, except for TteUPO. The rather low yields of MroUPO and Cg/UPO produced in S. cerevisiae could be increased substantially when using P. pastoris (MroUPO: 3-fold, Cg/UPO: 15-fold). The MthUPO production yield was improved 5-fold 
when produced in P. pastoris. Regarding TteUPO, the product titre was decreased in P. pastoris by approx. $20 \%$, however, still maintaining an overall high yield. The production titres of S. cerevisiae derived TteUPO (17 mg/L), and P. pastoris derived MthUPO (24 mg/L) are the highest yields for shake flask cultivation of recombinant fungal peroxygenases reported thus far. The transfer of the Pichia expression system to a fed-batch bioreactor might yield production levels at the $\mathrm{g} / \mathrm{L}$ scale, due to the higher cell densities achievable within this format as al ready demonstrated ${ }^{40}$. All proteins were purified using the TwinStrep-tag and analysed by SDS-PAGE (Supplementary Fig. 12). Highly pure enzyme preparations were obtained after one-step TwinStrep purification. Based on the successful production in both organisms, thermostability values (denaturation midpoint; $T_{m}$ ) of the four UPOs were assessed using differential scanning fluorimetry (Fig. 5a). Comparing the obtained values of the respective UPOs derived from both organisms were similar to a variation of 0.7 to $4.7^{\circ} \mathrm{C}$. The highest thermostability values were obtained for MroUPO with 67.4 and $66.0^{\circ} \mathrm{C}$ for S. cerevisiae and P. pastoris, respectively. The two UPOs derived from thermophilic fungi, MthUPO and TteUPO, exhibited no superior thermostability when compared to the closest related enzyme Cg/UPO. TteUPO revealed the lowest thermostability in the tested group with 44.6 and $49.3^{\circ} \mathrm{C}$ for S. cerevisiae and $P$. pastoris, respectively.

Enantioselective hydroxylation of an $\mathbf{N}$-protected phenethylamine on a preparative scale. To gain insights into the ability of the enzymes to convert industriallyrelevant molecules in an enantioselective manner, we selected $\mathrm{N}$-protected phenethylamine as a substrate. The hydroxylation of phenethylamine derivatives at the benzylic position provides access to a plethora of pharmaceutically important classes like beta-blockers and sympathomimetics ${ }^{47}$.

The peroxygenases AaeUPO*, MroUPO, Cg/UPO, MthUPO and TteUPO were produced in P. pastoris, purified and assessed for their activity on N-phthaloyl-phenethylamine. AaeUPO* and MroUPO exhibited no formation of the benzylic alcohol product, and TteUPO performed 60TON within an hour while achieving an enantioselectivity of $28 \%$ ee (Fig. 5b, Supplementary Figs. 16 and 18). Cg/UPO and MthUPO revealed the highest activities with 730 and 908 TON, respectively, within the $1 \mathrm{~h}$ reaction 
bioRxiv preprint doi: https://doi.org/10.1101/2020.07.22.216432; this version posted July 22,2020 . The copyright holder for this preprint

(which was not certified by peer review) is the author/funder, who has granted bioRxiv a license to display the preprint in perpetuity. It is made available under aCC-BY-NC-ND 4.0 International license.

setup (Supplementary Fig. 16). MthUPO showed an over-oxidation to the ketone amounting to 222 TON (Supplementary Fig. 17). The enantioselectivity proved to be excellent for Cg/UPO and MthUPO with $98.7 \%$ ee and $98.6 \%$ ee (Supplementary Fig. 18).

Harnessing the high production titre of MthUPO in P. pastoris $(24 \mathrm{mg} / \mathrm{L})$ in combination with the previously observed good substrate conversion and high enantioselectivity we aimed for the proof of

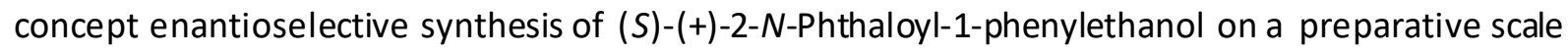
(Fig. 5c). In a first upscaling reaction ( $300 \mathrm{~mL}$ total volume) $0.125 \mathrm{~mol} \%$ of $M$ thUPO derived without further purification from concentrated $P$. pastoris supernatant were used as catalyst loading. The upscaled reaction $\left(30^{\circ} \mathrm{C} ; 1 \mathrm{~h}\right.$ ) led to the synthesis of $9.70 \mathrm{mg}(\mathrm{S})-(+)-2-N$-Phthaloyl-1-phenylethanol (57 $\%$ purified yield) and an enantiomeric excess of $98.6 \%$ (Supplementary Fig. 18). 
bioRxiv preprint doi: https://doi.org/10.1101/2020.07.22.216432; this version posted July 22, 2020. The copyright holder for this preprint (which was not certified by peer review) is the author/funder, who has granted bioRxiv a license to display the preprint in perpetuity. It is made available under aCC-BY-NC-ND 4.0 International license.

a

\begin{tabular}{cc}
\multicolumn{2}{c}{ S. cerevisiae } \\
\hline Production titer [mg/L] & $\mathrm{T}_{\mathrm{m}}\left[{ }^{\circ} \mathrm{C}\right]$ \\
\hline 0.35 & $67.4 \pm 0.3$ \\
0.6 & $61.2 \pm 0.6$ \\
5 & $58.1 \pm 0.1$ \\
17 & $44.6 \pm 0.7$
\end{tabular}

b

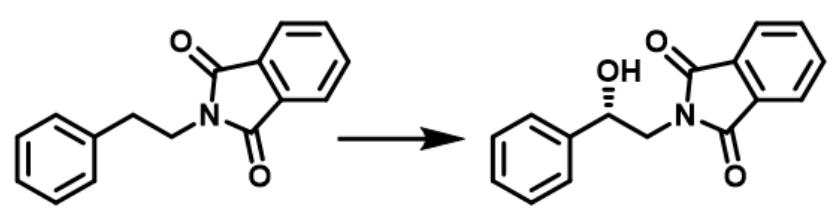

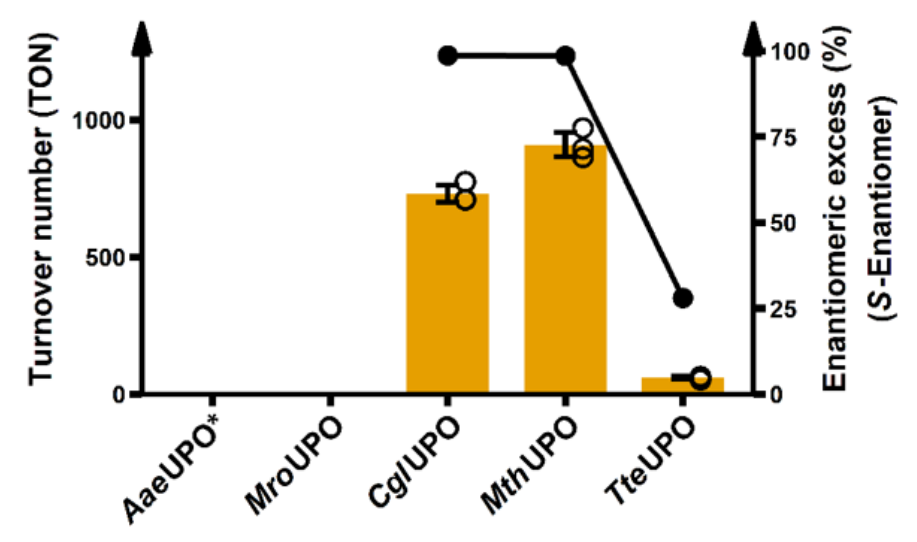

P. pastoris

\begin{tabular}{|c|c|}
\multicolumn{2}{c}{ P. pastoris } \\
\hline Production titer $[\mathrm{mg} / \mathrm{L}]$ & $\mathrm{T}_{\mathrm{m}}\left[{ }^{\circ} \mathrm{C}\right]$ \\
\hline 1.1 & $66.0 \pm 0.1$ \\
9 & $61.9 \pm 0.1$ \\
24 & $55.5 \pm 0.9$ \\
14 & $49.3 \pm 0.2$ \\
\hline
\end{tabular}

C

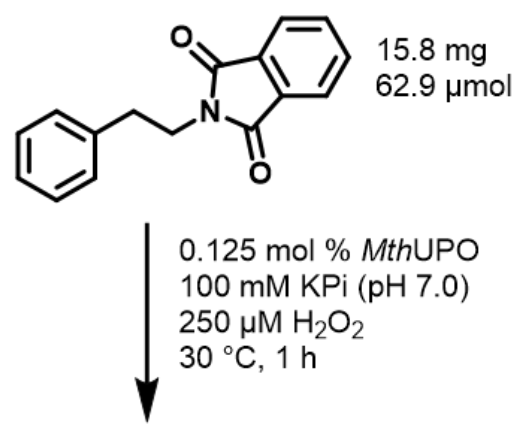<smiles>O=C1c2ccccc2C(=O)N1C[C@H](O)c1ccccc1</smiles>

$9.7 \mathrm{mg}(57 \%)$ $98.6 \%$ ee

Fig. 5 Expression yields and thermostabilities of UPOs derived from the different yeast systems and conversion of a phenethylamine derivative on analytical and preparative scale. a Comparison of volumetric production titre of recombinant UPOs in shake flask scale $(1 \mathrm{~L})$ between $\mathrm{S}$. cerevisiae (episomal construct) and $P$. pastoris (integrative construct) as obtained after ultrafiltration of the respective culture supernatant. UPOs were produced and secreted utilising their natural signal peptide (MroUPO and Cg/UPO) or a previously identified suitable exogenous signal peptide Mth UPO (Sce- $\alpha$ Galactosidase) and TteUPO (S. cerevisiae: CCi-UPO; P. pastoris: Sce-Prepro). For all P. pastoris production setups the methanol inducible promoter $P$ CAT1 was utilised. Thermal denaturation midpoints $\left(T_{m}\right)$ for the four UPOs produced in both organisms were determined in biological triplicates using purified protein samples (in $100 \mathrm{mM}$ potassium phosphate; $\mathrm{pH}$ 7.0) using differential scanning fluorimetry (DSF). b Bar chart showing turnover number within one hour for the benzylic hydroxylation of N-phthaloyl-phenethylamine by P. pastoris produced AaeUPO*, MroUPO, Cg/UPO, MthUPO and TteUPO. Turnover data are mean \pm s.d. of measurements made in triplicates. TON determined by GC-MS and ee \% by chiral HPLC (Supplementary Figs. 16-18). c Preparative scale conversion of $N$-phthalimide protected phenethylamine using $P$. pastoris produced MthUPO.

\section{Discussion}

Fungal unspecific peroxygenases (UPOs) have gained substantial interest as versatile hydroxylation catalyst since their initial discovery 16 years ago $^{2}$. The most significant limitation for the wider application of UPOs arguably remains the heterologous production utilising a fast-growing host. Thus far, only one UPO could be produced and engineered within a system amenable to high throughput: the S. cerevisiae secretion variant AaeUPO*6. 
Building on the therein developed expression setup, we started our endeavour to construct a versatile UPO secretion system. The constructed Golden Gate-based platform consists of a signal peptide library (Module 1), UPO genes (Module 2) and protein-tags (Module 3). This format enabled the first report of successful yeast secretion of six UPOs - two of them (MthUPO and TteUPO) derived from genome, and secretome data had not been characterised as UPOs before ${ }^{39}$. The whole expression platform could be subsequently transferred to P. pastoris, resulting in excellent UPO expression yields allowing for preparative scale hydroxylation reactions.

Since the only enzyme out of the panel that could not be produced (CciUPO) belongs to the group of long-type UPOs, and it previously took considerable effort to engineer the long-type UPO AaeUPO towards secretion in yeast, one could argue that the heterologous production of long-type UPOs seems to be more challenging. In fact, MroUPO, Cg/UPO, MthUPO and TteUPO, which could be initially produced in yeast and characterised within the scope of this work, all belong to the class of short-type UPOs. Recent work in our laboratory suggests that gene shuffling of long-type UPOs can offer a viable option to obtain a library of active and structurally diverse long-type UPOs expanding the panel of available recombinant peroxygenases ${ }^{48}$. The hypothesised pivotal role of the employed signal peptides for the successful secretion of UPOs was manifested within this study. Even in case of the laboratory evolved peroxygenase AaeUPO* harbouring an evolved signal peptide, the secretion could be further improved utilising the signal peptide Gma-UPO derived from another UPO by 2.2-fold in S. cerevisiae and even 6-fold in P. pastoris. The significance of a suitable signal peptide-gene combination is moreover underlined by the observation that almost all of the 17 tested signal peptides proved to be functional in combination with at least one UPO gene. The studies revealed substantial differencesin signal peptide acceptance and promiscuity among the different UPOs. Whereas AaeUPO* only showed pronounced activity in combination with two signal peptides (Aae-UPO* and Gma-UPO) other UPOs like MthUPO and TteUPO could be produced when combined with multiple and diverse signal peptides regarding sequence length and composition of the overall tested panel. Although all previously identified signal peptide-gene combinations led to productive secretion in Pichia pastoris as well, 
subtle differences and preferences were shown by a signal peptide shuffling for MthUPO and TteUPO in P. pastoris. Interestingly, the $\alpha$ factor leader signal peptide (Sce-Prepro), which is often used as a gold standard signal peptide for target protein secretion in P. pastoris ${ }^{42,43}$, was only identified as a top hit in combination with TteUPO.

The GFP11 detection tag proved to be an indispensable asset to distinguish secretion from activity ${ }^{30}$. Between different UPOs, the variation in fluorescence could be further pronounced based on different accessibilities of the split-GFP-tag. Thistendency was shown for AaeUPO* where the TwinStrep-GFP11 tag (59 amino acids) yielded a 4-fold increased signal intensity relative to the shorter GFP11 tag (27 amino acids). In some cases, like Cg/UPO (Fig 2a), the fluorescence response greatly differed from the activity depending on the employed signal peptide. This observation might be explained by different cleavage patterns at the $\mathrm{N}$-terminus depending on the respective signal peptide leading to slightly altered overall structures and hence activities of the mature, processed enzyme.

The peroxygenases TteUPO and MthUPO displayed unprecedented expression levels in S. cerevisiae and P. pastoris, even outperforming the secretion engineered enzyme AaeUPO*6. The adaptation to episomal plasmid expression in P. pastoris proved that the entire modular system could be readily transferred to other organisms. The application in P. pastoris furthermore paves the way towards future-directed evolution enterprises entirely performed in P. pastoris, further streamlining the workflow from gene discovery to construct identification and large scale protein production. In comparison to the S. cerevisiae based episomal system, the P. pastoris based episomal plasmid expression of MthUPO retained $60 \%$ of the activity (Fig. 4e). However, there is still plenty of potential for P. pastoris production optimisation utilising different promoters, carbon sources, induction and cofeeding strategies ${ }^{46,49}$. A substantial influence of the promoter-signal peptide combination was observed, as shown for TteUPO in Fig. 4d. This impact represents an aspect that can be further investigated in detail, for example, by expanding the modular system, including an additional shuffling library for promoters. Production of MthUPO utilising the integrative plasmid led to substantially improved production when compared to the episomal counterpart. Nevertheless, the obtained 
interclonal variation is substantial, rendering the episomal plasmid expression more suitable for high throughput endeavours (Fig. 4c).

The relevance of expanding the scope of recombinant UPOs is reflected by the fact, that $\mathrm{Cg} / \mathrm{UPO}$, MthUPO and TteUPO displayed a different substrate specificity when compared to the wellcharacterised enzyme AaeUPO* (Fig. 3). For the benzylic hydroxylation of the homologous phenylalkane row, ranging from phenylethane to phenylpentane AaeUPO* displayed the highest activity on phenylethane and only traces of product for phenylbutane and phenylpentane conversion. The enzymes Cg/UPO, MthUPO and TteUPO on the contrary, displayed the lowest activities for phenylethane and highest for phenylbutane and -pentane conversion, respectively. TteUPO furthermore catalyses the formation of the opposite alcohol enantiomer compared to the other UPOs for the conversion of phenylpropane to phenylpentane. Good activities and excellent enantioselectivities could also be achieved when challenging the enzymes for the benzylic hydroxylation of $\mathrm{N}$-phthalimide protected phenethylamine for $\mathrm{Cg} / \mathrm{UPO}$ and $\mathrm{Mth}$ UPO. This observation is vastly different from AaeUPO*, displaying no product formation and no known enantioselective conversion of substrates of similar structure. High UPO production yields in P. pastoris enabled the preparative conversion of a phenethylamine derivative by MthUPO.

In summary, these observations prove that the built workflow from UPO gene, followed by identification of suitable expression constructs via signal peptide shuffling in combination with high throughput screening in S. cerevisiae as well as $P$. pastoris and subsequent production upscaling can lead to highly enantioselective preparative product formations of pharmaceutically valuable building blocks.

In the future, this workflow could be applied to other UPO genes or generally genes of interest, which are suitable for production in yeast, especially for proteins that might require efficient posttranslational modifications such as glycosylation and disulfide linkage. Besidestarget protein secretion, the expression plasmids al so allow for intracellular production when no signal peptide is attached. To allow other researchers to harness the modular yeast system, we deposited all relevant plasmids 
(signal peptides, protein tags and expression plasmids) as a kit with the non-profit plasmid repository Addgene (Yeast Secret and Detect Kit).

\section{References}

$1 \mathrm{Ni}$, Y. et al. Peroxygenase-Catalyzed Oxyfunctionalization Reactions Promoted by the Complete Oxidation of Methanol. Angew. Chem. Int. Ed. 55, 798-801 (2016).

2 Ullrich, R., Nuske, J., Scheibner, K., Spantzel, J. \& Hofrichter, M. Novel haloperoxidase from the agaric basidiomycete Agrocybe aegerita oxidizes aryl al cohols and aldehydes. Appl. Environ. Microbiol. 70, 4575-4581 (2004).

3 Zhang, W. et al. Selective aerobic oxidation reactions using a combination of photocatalytic water oxidation and enzymatic oxyfunctionalisations. Nat. Catal. 1, 55-62 (2018).

4 Wang, Y., Lan, D., Durrani, R. \& Hollmann, F. Peroxygenases en route to becoming dream catalysts. What are the opportunities and challenges? Curr. Opin. Chem. Biol. 37, 1-9 (2017).

5 Ullrich, R. et al. Side chain removal from corticosteroids by unspecific peroxygenase. J. Inorg. Biochem. 183, 84-93 (2018).

6 Molina-Espeja, P. et al. Directed evolution of unspecific peroxygenase from Agrocybe aegerita. Appl. Environ. Microbiol. 80, 3496-3507 (2014).

7 Martin-Diaz, J., Paret, C., Garcia-Ruiz, E., Molina-Espeja, P. \& Alcalde, M. Shuffling the Neutral Drift of Unspecific Peroxygenase in Saccharomyces cerevisiae. Appl. Environ. Microbiol. 84 (2018).

8 Molina-Espeja, P. et al. Synthesis of 1-Naphthol by a Natural Peroxygenase Engineered by Directed Evolution. ChemBioChem 17, 341-349 (2016).

9 Gomez De Santos, P. et al. Selective Synthesis of the Human Drug Metabolite 5'Hydroxypropranol ol by an Evolved Self-Sufficient Peroxygenase. ACS Catal. 8, 4789-4799 (2018).

10 Gomez De Santos, P. et al. Benchmarking of laboratory evolved unspecific peroxygenases for the synthesis of human drug metabolites. Tetrahedron 75, 1827-1831 (2019).

11 Rapoport, T. A., Jungnickel, B. \& Kutay, U. Protein transport across the eukaryotic endoplasmic reticulum and bacterial inner membranes. Annu. Rev. Biochem. 65, 271-303 (1996).

12 Williams, E. J. B., Pal, C. \& Hurst, L. D. The molecular evolution of signal peptides. Gene 253, 313-322 (2000).

13 Rakestraw, J. A., Sazinsky, S. L., Piatesi, A., Antipov, E. \& Wittrup, K. D. Directed evolution of a secretory leader for the improved expression of heterologous proteins and full-length antibodies in Saccharomyces cerevisiae. Biotechnol. Bioeng. 103, 1192-1201 (2009).

14 Mateljak, I., Tron, T. \& Alcalde, M. Evolved al pha-factor prepro-leaders for directed laccase evolution in Saccharomyces cerevisiae. Microb. Biotechnol. 10, 1830-1836 (2017).

15 Vina-Gonzalez, J., Elbl, K., Ponte, X., Valero, F. \& Alcalde, M. Functional expression of arylalcohol oxidase in Saccharomyces cerevisiae and Pichia pastoris by directed evolution. Biotechnol. Bioeng. 115, 1666-1674 (2018).

16 Vina-Gonzalez, J., Gonzalez-Perez, D., Ferreira, P., Martinez, A. T. \& Alcalde, M. Focused Directed Evolution of Aryl-Alcohol Oxidase in Saccharomyces cerevisiae by Using Chimeric Signal Peptides. Appl. Environ. Microbiol. 81, 6451-6462 (2015).

17 González-Benjumea, A. et al. Fatty acid epoxidation by Collariella virescens peroxygen ase and heme-channel variants. Catal. Sci. Techn. (2020).

18 Linde, D. et al. Two New Unspecific Peroxygenases from Heterologous Expression of Fungal Genes in Escherichia coli. Appl. Environ. Microbiol. 86, e02899-02819 (2020). 
Engler, C., Gruetzner, R., Kandzia, R. \& Marillonnet, S. Golden Gate Shuffling: A One-Pot DNA Shuffling Method Based on Type Ils Restriction Enzymes. PLoS One 4, e5553 (2009). Engler, C., Kandzia, R. \& Marillonnet, S. A one pot, one step, precision cloning method with high throughput capability. PLoS One 3, e3647 (2008).

Werner, S., Engler, C., Weber, E., Gruetzner, R. \& Marillonnet, S. Fast track assembly of multigene constructs using Golden Gate cloning and the MoClo system. Bioeng. Bugs 3, 3843 (2012).

Sarrion-Perdigones, A. et al. GoldenBraid: an iterative cloning system for standardized assembly of reusable genetic modules. PLoS One 6, e21622 (2011).

Andreou, A. I. \& Nakayama, N. Mobius Assembly: A versatile Golden-Gate framework towards universal DNA assembly. PLoS One 13, e0189892 (2018).

Pollak, B. et al. Loop assembly: a simple and open system for recursive fabrication of DNA circuits. New Phytol. 222, 628-640 (2019). van Dolleweerd, C. J. et al. MIDAS: A Modular DNA Assembly System for Synthetic Biology. ACSSynth. Biol. 7, 1018-1029 (2018). Ligase and Application to DNA Assembly. ACS Synth. Biol. 7, 2665-2674 (2018).

Püllmann, P. et al. Golden Mutagenesis: An efficient multi-site-saturation mutagenesis approach by Golden Gate cloning with automated primer design. Scientific Reports $\mathbf{9}, 10932$ (2019). for Standardized Assembly of Multigene Constructs. PLoS One 6, e16765 (2011). Cabantous, S. \& Waldo, G. S. In vivo and in vitro protein solubility assays using split GFP. Nat. Methods 3, 845-854 (2006). Screening of Protein Engineering Libraries by Split-GFP Direct Crude Cell Extract Data Normalization. Chem. Biol. 22, 1406-1414 (2015).

Gonzalez-Perez, D., Molina-Espeja, P., Garcia-Ruiz, E. \& Alcalde, M. Mutagenic Organized Recombination Process by Homologous IN vivo Grouping (MORPHING) for directed enzyme evolution. PLoS One 9, e90919 (2014).

Poraj-Kobiel ska, M., Kinne, M., Ullrich, R., Scheibner, K. \& Hofrichter, M. A spectrophotometric assay for the detection of fungal peroxygenases. Anal. Biochem. 421, 327-329 (2012).

Schmidt, T. G. M. \& Skerra, A. The Strep-tag system for one-step purification and high-affinity detection or capturing of proteins. Nat. Protoc. 2, 1528-1535 (2007). Hochuli, E., Bannwarth, W., Döbeli, H., Gentz, R. \& Stüber, D. Genetic Approach to Facilitate Purification of Recombinant Proteins with a Novel Metal Chelate Adsorbent. Biotechn. 6, 1321-1325 (1988). purification of recombinant proteins from cell culture supernatants. Protein Expr. Purif. 92, 54-61 (2013). Marasmius rotula. AMB Expr. 1, 31-31 (2011).

37 Kiebist, J.et al. A Peroxygenase from Chaetomium globosum Catalyzes the Selective Oxygenation of Testosterone. ChemBioChem 18, 563-569 (2017).

38 Babot, E. D., del Rio, J. C., Kalum, L., Martinez, A. T. \& Gutierrez, A. Oxyfunctionalizat ion of aliphatic compounds by a recombinant peroxygenase from Coprinopsis cinerea. Biotechnol. Bioeng. 110, 2323-2332 (2013).

39 Berka, R. M. et al. Comparative genomic analysis of the thermophilic biomass-degrading fungi Myceliophthora thermophila and Thi elavia terrestris. Nat. Biotechn. 29, 922-927 (2011). 

system for engineering and producing unspecific peroxygenase. Enzyme Microb Technol 7374, 29-33 (2015).

41 Prielhofer, R. et al. GoldenPiCS: a Golden Gate-derived modular cloning system for applied synthetic biology in the yeast Pichia pastoris. BMC Syst. Biol. 11, 123 (2017).

42 Obst, U., Lu, T. K. \& Sieber, V. A Modular Toolkit for Generating Pichia pastoris Secretion Libraries. ACS Synth. Biol. 6, 1016-1025 (2017).

43 Ahmad, M., Hirz, M., Pichler, H. \& Schwab, H. Protein expression in Pichia pastoris: recent achievements and perspectives for heterologous protein production. Appl. Microbiol. Biotechnol. 98, 5301-5317 (2014).

44 Camattari, A. et al. Characterization of a panARS-based episomal vector in the methylotrophic yeast Pichia pastoris for recombinant protein production and synthetic biology applications. Microb. Cell Fact. 15, 139 (2016).

45 Yang, J. et al. Hygromycin-resistance vectors for gene expression in Pichia pastoris. Yeast 31, 115-125 (2014).

46 Vogl, T. et al. A Tool box of Diverse Promoters Related to Methanol Utilization: Functionally Verified Parts for Heterologous Pathway Expression in Pichia pastoris. ACS Synth Bio/5, 172186 (2016).

47 Schäfer, B. Naturstoffe der chemischen Industrie. (Elsevier, München, 2007).

48 Knorrscheidt, A. et al. Identification of novel unspecific peroxygenase chimeras and unusual YfeX axial heme ligand by a versatile high-throughput GC-MS approach. ChemCatChem (2020). optimization. Nat. Commun. 9, 3589 (2018).

\section{Acknowledgment}

M.J.W and A.K. thank the Bundesministerium für Bildung und Forschung („Biotechnologie 2020+ Strukturvorhaben: Leibniz Research Cluster", 031A360B and 031A360E) for generous funding. P.P. thanks the Landesgraduiertenförderung Sachsen-Anhalt for a PhD scholarship. J.M. thanks the Friedrich-Naumann-Stiftung for a PhD scholarship. Prof. Jürgen Pleiß (University of Stuttgart), Prof. Dirk Holtmann and Sebastian Bormann (DECHEMA Frankfurt) are kindlyacknowledged for sharing putative and described UPO gene sequences. We would like to thank Cătălin Voiniciuc (Leibniz Institute of Plant Biochemistry Halle) for fruitful discussions regarding protein production in Pichia pastoris and furthermore providing Pichia plasmid parts and the X33-strain. Prof. Karin Breunig (Martin Luther University Halle-Wittenberg) is kindly acknowledged for generously supplying genomic DNA of $K$. lactis. We would like to especially thank Anja Ehrlich (Leibniz Institute of Plant Biochemistry Halle) for outstanding technical support and patience regarding chiral HPLC analyis of phenethylamine 
conversions. Furthermore, Prof. Markus Pietzsch and Dr. Franziska Seifert (Martin Luther University Halle-Wittenberg) are kindly acknowledged for discussions and providing access to the DSF device for thermostability measurements. Our sincere gratitude also goes to Prof. Martin Hofrichter and Dr. Harald Kellner (Technical University of Dresden)for discussions and providing the protein sequence of MweUPO. Dr. Swanhild Lohse (IPB Halle) is acknowledged for the initial construction of the utilised pAGT572 backbone structure of episomal S. cerevisiae plasmids.

Author contributions. M.J.W and P.P. designed the research. P.P. performed all experiments apart from the enzymatic conversions in Figure 3 (performed by A.K.), Figure 5 (performed by J.M. and P.R.P. and co-designed by B.W.) and the protein identification by MS (performed by W.H.). P.P. and S.M. designed the modular Golden Gate yeast system and M.A. developed the 96-well S. cerevisiae expression system. M.J.W. and P.P. wrote the manuscript. All authors contributed to the proofreading of the manuscript.

Competing interests. Evolved AaeUPO* used in the current study is protected by CSIC patent WO/2017/081355 (licensed in exclusivity to EvoEnzyme S.L).

Materials \& Correspondence. Correspondence and requests for materials should be addressed to M.J.W.

Additional information. Supplementary information is available.

Data availability. The authors declare that the data supporting the findings of this study are available within the paper and its Supplementary Information files. Source data are available from the corresponding author upon reasonable request.

\section{ONLINE METHODS}

Chemicals. Solvents were used as received without further purification. Ethyl acetate and acetone were utilised in GC ultra-grade ( $\geq 99,9 \%)$ from Carl Roth (Karlsruhe, DE). Acetonitrile was purchased from Merck (Darmstadt, DE) in gradient grade for LC ( $\geq 99,9 \%)$. Deuterated solvents for NMR spectroscopy were purchased from Deutero (Kastellaun, DE). All further reaction chemicals were 
purchased either from Sigma-Aldrich (Hamburg, DE), TCI Chemicals (Tokyo, JP), Merck (Darmstadt, DE), abcr (Karlsruhe, DE) or Fluka Chemika (Buchs, $\mathrm{CH}$ ) and used as received. (R)-(+)-1-Phenyl-1-propanol ( $98 \%$ purity) was purchased from abcr (Karlsruhe, DE). 1-Naphthol ( $99 \%$ purity) was purchased from Merck (Darmstadt, DE). Naphthalene (99\% purity), 1,4-Naphthoquinone (97\% purity), Propyl benzene (99\% purity; GC), Butyl benzene ( $\geq 99 \%$ purity), Ethyl benzoate (analytical standard), (R) -(+)-1-Phenyl1-butanol (97 \% purity), 2,6-Dimethoxyphenol (99\% purity), 5-Nitro-1,3-benzodioxole (98\% purity), Styrene (>99\% purity) and Hydrogen peroxide $(30 \%(v / v))$ were purchased from Sigma-Aldrich. $( \pm)-1-$ Phenyl-1-propanol (98\% purity) was purchased from Fluka Chemika. Pentyl benzene ( $>98 \%$ purity), Ethyl benzene (>99\% purity), ( \pm )-1-Phenyl-1-pentanol (>98\% purity), ( \pm )-1-Phenylethyl alcohol (>98 $\%$ purity), ( \pm )-1-Phenyl-1-butanol (>98\% purity), (R)-(+)-1-Phenylethyl alcohol (>98\% purity) and ( \pm )Styrene oxide (>98 \% purity) were purchased from TCI Europe (Eschborn, DE), all of them were used as received.

Lab ware. Specialised 96-well half deep well microtiter plates for yeast cell growth and protein expression (model type: CR1496c) were purchased from EnzyScreen (Heemstede, NL) and were sealed with a fitting CR1396b Sandwich cover.

Enzymes and cultivation media. For cultivation of E. coli cells terrific broth (TB) media from Carl Roth (Karlsruhe, DE) was used. For cultivation of S. cerevisiae cells D-Galactose, Peptone and Synthetic Complete Mixture (Kaiser) Drop-Out (-URA) were purchased from Formedium(Hunstanton, GB). Yeast nitrogen base (without amino acids) and Yeast extract were purchased from Carl Roth (Karlsruhe, DE). For P. pastoris cultivation Methanol (99,9\% Chromasolv purity grade) purchased from Honeywell Chemicals (Seelze, DE) was used as additional carbon source. PNGase F and Bsal were purchased from New England Biolabs (Ipswich, US). Bbsl and FastDigest Ascl were purchased from ThermoFisherScientific (Waltham, US) and T4 DNA Ligase from Promega (Madison, US).

Bacterial and Yeast strains. For all cloning purposes and plasmid propagation, E.coli DH10B cells (ThermoFisherScientific, Waltham, US) were utilised. The protein sfGFP1-10 was produced utilising the 
E.coli BL21(DE3) strain (ThermoFisherScientific, Waltham, US) capable of T7 promoter dependent target protein expression. In the case of all workregarding Saccharomyces cerevisiae, the diploidstrain INVSc1 (genotype: MATa his3D1 leu2 trp1-289 ura3-52 MAT his3D1 leu2 trp1-289 ura3-52) (ThermoFisherScientific, Waltham, US) was used. All work regarding Pichia pastoris was performed utilising the mut ${ }^{+}$Strain X-33 (ThermoFisherScientific, Waltham, US).

Oligonucleotides and Gene parts. All oligonucleotides were purchased in the lowest purificationgrade "desalted" and minimal quantity at Eurofins Genomics (Ebersberg, DE). The Pichia pastoris Cat1 promoter was purchased as a gene part from Twist Bioscience (San Francisco, US). The genes of the AaeUPO variant PaDa-I, GmaUPO, MweUPO and the sfGFP 1-10 gene were purchased as plasmidcloned genes from Eurofins Genomics (Ebersberg, DE). The genes of Cg/UPO, MthUPO and TteUPO were retrieved as codon optimised (S. cerevisiae codon usage) gene strands from Eurofins Genomics.

Achiral gas chromatography-mass spectrometry (GC-MS). Measurements were performed on a Shimadzu GCMS-QP2010 Ultra instrument (Shimadzu, Kyoto, JP) using a SH-Rxi-5Sil MS column (30 m $x 0.25 \mathrm{~mm}, 0.25 \mu \mathrm{m}$ film, Shimadzu, Kyoto, JP) or OPTIMA 5MS Accent column ( $25 \mathrm{~m} \times 0.20 \mathrm{~mm}, 0.20$ $\mu \mathrm{m}$ film, Macherey-Nagel, Düren, DE) and helium as carrier gas. $1 \mu \mathrm{l}$ of each sample was injected splitless with an injection temperature of $280^{\circ} \mathrm{C}$. The split/splitless uniliner inlets $(3.5 \mathrm{~mm}, 5.0 \times 95$ mm for Shimadzu GCs, deactivated wool) from Restek (Bad Homburg, DE) were utilised and regenerated if needed by CS-Chromatography (Langerwehe, DE). The temperature program was adjusted, as shown in Supplementary Table 5. The interface temperature was set to $290^{\circ} \mathrm{C}$. Ionisation was obtained by electron impact with a voltage of $70 \mathrm{~V}$, and the temperature of the ion source was $250{ }^{\circ} \mathrm{C}$. The MS is equipped with dual-stage turbomolecular pumps and a quadrupole enabling a selected ion monitoring acquisition mode (SIM mode). Calibration and quantification were implemented in SIM mode with the corresponding $\mathrm{m} / \mathrm{z}$ traces, as shown in Supplementary Table 5. The detector voltage of the secondary electron multiplier was adjustedin relation to the tuning results with perfluorotributylamine. The GC-MS parameter was controlled with GCMS Real Time Analysis, and 
for data evaluation, GCMS Postrun Analysis (GCMSsolution Version 4.45, Shimadzu, Kyoto, JP) was used.

Chiral gas chromatography-mass spectrometry (GC-MS). Measurements were performed on a Shimadzu GCMS-QP2020 NX instrument (Shimadzu, Kyoto, JP) with a Lipodex E column ( $25 \mathrm{~m} \times 0.25$ $\mathrm{mm}$, Macherey-Nagel, Düren, DE) and helium as carrier gas. $1 \mu$ l of each sample was injected splitless with an OPTIC-4 (Shimadzu, Kyoto, JP) injector utilising a temperature profile in the liner $\left(35^{\circ} \mathrm{C}, 1^{\circ} \mathrm{C} / \mathrm{s}\right.$ to $220^{\circ} \mathrm{C}$ hold $\left.115 \mathrm{~s}\right)$. The column temperature program was adjusted as shown in Supplementary Table 5. The interface temperature was set to $200^{\circ} \mathrm{C}$. Ionisation was obtained by electron impact with a voltage of $70 \mathrm{~V}$, and the temperature of the ion source was $250^{\circ} \mathrm{C}$. The MS is equipped with dual stage turbomolecular pumps and a quadrupole enabling a selected ion monitoring acquisition mode (SIM mode). Calibration and quantification were implemented in SIM mode with the corresponding $m / z$ traces, as shown in Supplementary Table 5. The detector voltage of the secondary electron multiplier was adjusted in relation to the tuning results with perfluorotributylamine. The GC-MS parameters were controlled with GCMS Real Time Analysis, and for data evaluation GCMS Postrun Analysis (GCMSsolution Version 4.45, Shimadzu, Kyoto, JP) was used.

Column and analytic thin layer chromatography. All solvents for column chromatography were purchased from Merck Millipore (Darmstadt, DE) and distilled prior to use. Column chromatography was carried out using Merck silica gel $60(40-63 \mu \mathrm{m})$. For analyticthin layer chromatography, Merck TLC silica gel 60 F254 aluminium sheets were used. Compounds were visualised by using UV light $(254 / 366 \mathrm{~nm})$.

Nuclear magnetic resonance (NMR). NMR spectra were recorded using a $400 \mathrm{MHz}$ Agilent DD2 400 NMR spectrometer at $25^{\circ} \mathrm{C}$. The chemical shifts of $1 \mathrm{H}$ NMR spectra are referenced on the signal of the internal standard tetramethylsilane $(\delta=0.000 \mathrm{ppm})$. Chemical shifts of $13 \mathrm{C}$ NMR spectra are referenced on the solvent residual signals of $\mathrm{CDCl}_{3}(\delta=77.000 \mathrm{ppm})$. 
bioRxiv preprint doi: https://doi.org/10.1101/2020.07.22.216432; this version posted July 22,2020 . The copyright holder for this preprint

(which was not certified by peer review) is the author/funder, who has granted bioRxiv a license to display the preprint in perpetuity. It is made available under aCC-BY-NC-ND 4.0 International license.

Electrospray ionisation mass spectrometry (ESI-MS). ESI mass spectra were recorded on an API3200

Triple Quadrupole mass spectrometer (AB Sciex) equipped with an electrospray ion source (positive spray voltage $5.5 \mathrm{kV}$, negative spray voltage $4.5 \mathrm{kV}$, source heater temperature $\left.400^{\circ} \mathrm{C}\right)$.

Specific optical rotation. Specific optical rotations of compounds were recorded on a P-2000 Digital Polarimeter (JASCO, Pfungstadt, DE) utilising a wavelength of $589 \mathrm{~nm}$.

Chiral HPLC. HPLC chromatograms were recorded on an Agilent High Performance LC (Agilent Technologies, Waldbronn, DE). The used chiral column material was Chiralpak AS-H HPLC (Daicel, Tokyo, JP) (25 cm x $4.6 \mathrm{~mm}$ ). Substances were dissolved in HPLC-grade isopropanol prior to analysis, and a sample volume of $5 \mu \mathrm{L}$ injected. The eluent (20\% isopropanol, $80 \% n$-hexane) was usedin a flow rate of $1 \mathrm{~mL} / \mathrm{min}$ with the runtime of $30 \mathrm{~min}$ at $30^{\circ} \mathrm{C}$.

Microwave reactions. Microwave reactions were carried out using an Initiator+ device (Biotage, Düsseldorf, DE). 